\title{
MORTALITY RISK AND CONSUMPTION BY COUPLES
}

\author{
Michael D. Hurd
}

Working Paper 7048

http://www.nber.org/papers/w7048

\section{NATIONAL BUREAU OF ECONOMIC RESEARCH 1050 Massachusetts Avenue \\ Cambridge, MA 02138 \\ March 1999}

This paper is a revision and extension of a paper presented at the IFS-Bank of Portugal Conference on the Microeconomics of Saving and Consumption Growth, Lisbon, November 1995, which, in turn, was based on my 1992a paper. Financial support from the National Institute on Aging is gratefully acknowledged. The views expressed in this paper are those of the authors and do not reflect those of the National Bureau of Economic Research.

(0) 1999 by Michael D. Hurd. All rights reserved. Short sections of text, not to exceed two paragraphs, may be quoted without explicit permission provided that full credit, including ${ }^{\circ}$ notice, is given to the source. 
Mortality Risk and Consumption by Couples

Michael D. Hurd

NBER Working Paper No. 7048

March 1999

JEL No. D9, E21

\section{ABSTRACT}

This paper proposes and analyzes a life-cycle model of consumption by couples. The model is considerably more complicated than the standard model for singles because it has to account for the welfare of a surviving spouse. The determinants of consumption are the survival paths of each spouse, bequeathable wealth, the flow of annuities both before and after the death of one of the spouses, a motive for bequeathing at the death of the surviving spouse, and the parameters of the utility functions of the couple and of each spouse if widowed. The analysis shows how consumption and the rate of change of bequeathable wealth react to variations in these determinants, and it compares the consumption level of a single person to a couple. Summaries of wealth change and consumption in panel data are given which offer general support for the lifecycle model.

Michael D. Hurd

RAND Corporation

1700 Main St.

Santa Monica, CA 90407

and NBER

mhurd@rand.org 


\section{Introduction.}

The goal of this paper is to analyze a model to explain consumption by couples. It is an extension of the model for singles by Yaari (1965), and therefore emphasizes the role of mortality risk. It also allows for a what I call a "true" bequest motive, bequeathing by a couple to the next generation, or at least to others outside of their own two-person household. The distinction between a true bequest motive and simply the provision for a surviving spouse is important because the surviving spouse is the extension of the original household, and the survivor had a direct influence in choosing the consumption by the couple when the deceased spouse was alive. This makes the situation very different from a true bequest where the bequest depends at least partly on motives other than purely selfish consumption and where the bequeathed has no direct control on the consumption by the household. There is also a difference in the planning horizon which causes important differences for public policy: if a couple desires to give bequests to their children, and possibly to their grandchildren, they will act in a very different way in response to, say, an increase in Social Security benefits than if they only want to bequeath to each other.

There is, of course, a voluminous literature on the life-cycle model, but almost without exception it deals with the life cycle of an individual, despite the fact that most of the population is married. ${ }^{1}$ When mortality risk is low this is not very important for a wide range of research questions, but among the elderly where mortality risk is high the model of a single person is not an accurate description of the decision problem facing a couple. ${ }^{2}$ In many of the papers the focus of the work is on other aspects of uncertainty such as uninsured medical expenses, and the further complication of considering a couple may make the models untractable; but in other papers the focus is on mortality risk, and thinking of just the life-cycle of a single person may lead to inaccurate conclusions. For example, a number of writers have concluded that the rate of dissaving is so low that a bequest motive must be important (Bernheim, 1987; Modigliani, 1986, 1988; Kotlikoff, 1988; Kotlokoff and Summers, 1988). Yet at those ages when mortality risk is high enough that the life cycle model predicts substantial dissaving, the rate of transition from couples to singles is also high. Without taking into account the change in composition with age, it is difficult to assess what the

\footnotetext{
${ }^{1}$ Exceptions are Kotlikoff and Spivak, 1981, and Brown and Poterba, 1998.

${ }^{2}$ See for example, Blundell, Browning and Meghir, 1994; Hubbard, Skinner and Zeldes, 1995; Levin, 1995; Attanasio and Browning, 1995; Laitner and Juster, 1996. In their lengthy review of household saving, Browning and Lusardi (1996) discuss in a paragraph the issue of the age of the household when there is more than one member, but go no further.
} 
appropriate rate of dissaving should be.

The setting for this paper is of a retired couple that has bequeathable wealth and annuities. For most of the analysis, I will assume that the annuities are indexed, as in the U.S. Social Security system. I will further assume that there is a borrowing constraint such that bequeathable wealth cannot become negative, even though the couple has a claim on Social Security benefits. That is, future benefits cannot be use as collateral for a consumption loan. ${ }^{3}$ The only uncertainty is mortality risk.

The determinants of consumption and, therefore, of wealth change are mortality risk, bequeathable wealth, the path of annuities including Social Security, and taste parameters particularly a bequest motive. The objective is to analyze how variation in each of these affects consumption and wealth paths. Because the ultimate objective of this line of work is to use the model in estimation, the analysis will use methods that can easily translate into empirical models.

The analysis shows that a true bequest motive will reduce the rate of wealth decumulation by couples just as it does among singles. It is much more difficult to analyze how the rate of wealth decumulation by the couple will change with age because the rate depends on the ages of both spouses and on the economic circumstances facing each after widowing. Nonetheless, the wealth of couples should decline at least at advanced age. A comparison of the rates of consumption and dissaving by singles and by couples depends on the economic circumstances of each, as well as utility parameters and mortality risk, so that no universal prediction can be made. In a leading example, greater risk aversion, smaller returns-to-scale in consumption, and a low risk of extreme longevity should lead to greater dissaving by couples relative to singles.

The theoretical analyses form the basis of some informal tests of the life cycle model ( $\mathrm{LCH}$ ) of consumption by couples and by singles. I give some results on consumption levels and consumption change and on wealth decumulation by couples and singles that support the LCH.

2. Model of Consumption by Singles.

The optimal choice of consumption by a couple will depend on the value of wealth to the surviving spouse in the event that one spouse dies. The value of wealth will depend on the subsequent choice of consumption made by the surviving spouse, and the optimal choice is the solution to the utility maximization problem by a single person. Therefore, the analysis of the couple's model requires a prior analysis of the

\footnotetext{
${ }^{3}$ In the U.S., Social Security benefits cannot be used as collateral.
} 
single's model, so I first spend considerable time analyzing the single's model. ${ }^{4}$

The single's problem is to maximize in the consumption path $\left\{c_{t}\right\}$ expected lifetime utility

$$
\int_{0}^{N} u\left(c_{t}\right) e^{-\rho t} a_{t} d t+\int_{0}^{N} V\left(w_{t}\right) e^{-\rho t} m_{t} d t
$$

The first term is expected discounted utility from consumption.

$u(\cdot)=$ the utility flow from consumption;

$\rho=$ the subjective time rate of discount;

$a_{t}=$ the probability of being alive at $t$;

$N=$ the maximum age to which anyone can live $\left(a_{N}=0\right)$

The second term is the expected discounted utility of bequests.

$V(\cdot)=$ utility from bequests which may depend on the economic status of children in an altruistic model or in a strategic bequest model;

$w_{t}=$ bequeathable wealth at $t$

$m_{t}=$ probability of dying at $t$.

I will make the usual assumptions about $u(\cdot): u^{\prime}>0$ and becoming arbitrarily large as $c \rightarrow 0$, and $u^{\prime \prime}<0$. I will assume that $V^{\prime}>0$ and that $V^{\prime \prime}<0$, but that $V^{\prime}(0)$ is bounded. This is reasonable in that those outside the household have incomes of their own, so that if they receive no bequest they still can consume.

The constraints on the maximization are:

$w_{0}$ is initial bequeathable wealth which is given;

$w_{t} \geq 0 \forall t$ is the nonnegativity constraint;

$$
\frac{d w_{t}}{d t}=r w_{t}-c_{t}+A_{t}
$$

in which

$r=$ real interest rate (constant and known)

$A_{t}=$ flow of annuities at time $t$.

${ }^{4}$ This section is an extension of my 1989 paper, which was based on Yaari, 1965. 
The nonnegativity constraint on bequeathable wealth can be justified by a legal ban on borrowing against Social Security benefits. In addition, in data very few are observed with negative wealth, and the few tend to have negative wealth as the result of negative business wealth. This is likely to be the result of unanticipated losses rather than borrowing for consumption purposes. The importance of taking account of the corner solution $\left(w_{t}=0\right)$ is seen from the fraction of single elderly with approximately zero nonhousing wealth. In 1993 , about $25 \%$ of those aged $70-79$ and about $50 \%$ of those aged $90-100$ had wealth less than $\$ 1,000 .^{5}$

The model places considerable emphasis on annuity income, which is based on the empirical observation of its importance: in 1994 ninety-four percent of the elderly (65 or over) had some annuity or pension income; seventy-nine percent had more than half of their income from annuities or pensions. I take annuities as given exogenously for the simple reason that in the U.S. almost no one has self-purchased annuities. ${ }^{6}$

The solution to the single's problem is:

$$
\begin{aligned}
& \frac{d u_{t}}{d t}=u_{t}\left(h_{t}+\rho-r\right)-h_{t} V_{t} \quad \text { for } w_{t}>0 \\
& c_{t}=A_{t} \quad \text { for } w_{t}=0
\end{aligned}
$$

and $w_{0}$ given. $^{\top}$ Here

$u_{t}=$ marginal utility of consumption at time $t$

$h_{t}=m_{t} / a_{t}=$ mortality risk (mortality hazard)

$V_{t}=$ marginal utility of bequests at time $t$.

A typical solution as would be found in data is shown in Figure 1. At $T$ bequeathable wealth has been consumed, and consumption equals annuity income after $T .^{8}$

\footnotetext{
${ }^{5}$ Author's calculation based on wave 1 of the Survey of the Asset and Health Dynamics among the Oldest-Old. See Soldo, Hurd, Rodgers and Wallace, forthcoming.

${ }^{6}$ The high load factor on self-purchases annuities is thought to be substantially responsible (Friedman and Warshawsky, 1988; Hurd, 1990). Taking them as given for this analysis is, of course, a separate issue from their econometric exogeneity in a particular empirical application.

${ }^{7}$ See Hurd, 1989, for a derivation.

${ }^{8}$ If at some age greater than $T$ annuity income declines more rapidly than the desired consumption path, the solution will be more complicated: a lower consumption path could be optimal, and consumption could fall below $A_{T}$. This is rather unlikely, however, as it would require both substantial inflation and large holdings of unindexed annuities.
} 


\subsection{No bequest motive. ${ }^{9}$}

As long as $w_{t}>0$, marginal utility will follow the path in (2), but with the restriction that the marginal utility of bequests is zero; that is, $V_{t}=0$. In that case, if $\rho>r$

$$
\frac{d u_{t}}{d t}>0 \text { and, therefore, } \frac{d c_{t}}{d t}<0 \text {. }
$$

That is, consumption will always decline.

If $\rho<r$, then $\frac{d u_{t}}{d t}<0$ when $h_{t}$ is small as would be the case at young ages. At older ages, however, $h_{t}$ is approximately exponential so that at some age $\tau$,

$$
h_{\tau}+\rho-r=0, \text { and } \frac{d u_{t}}{d t}=0 \text { at } t=\tau .
$$

For $t>\tau, \frac{d u_{t}}{d t}>0$ and $\frac{d c_{t}}{d t}<0$.

Over a small interval $(t, t+\delta)$ where $w_{t}>0$

$$
u_{t}=u_{t+\delta} \frac{a_{t+\delta}}{a_{t}} e^{\delta(r-\rho)} \approx u_{t+\delta} e^{\delta\left(r-\rho-h_{t}\right)}
$$

Mortality risk, $h_{t}$, acts like an increase in the discount rate.

The wealth path associated with the optimal consumption path is found from the equation of motion of wealth (1). Let $A_{t}=A$, a constant, which would be the case for many in the U.S. whose only annuity is Social Security. ${ }^{10}$ Then

$$
\frac{d^{2} w_{t}}{d t^{2}}=r \frac{d w_{t}}{d t}-\frac{d c_{t}}{d t}
$$

At some age, $\tau, \frac{d c_{t}}{d t}<0$. If

$$
\left.\frac{d w_{t}}{d t}\right|_{\tau}>0 \text { then } \frac{d^{2} w_{t}}{d t^{2}}>0 \forall t>\tau \Rightarrow \frac{d w_{t}}{d t}>0 \forall t>\tau \Rightarrow w_{N}>0
$$

${ }^{9}$ The analysis of this section is a generalized version of the analysis in Bernheim (1987).

${ }^{10}$ The annuity income of singles is rather effectively indexed: in 1994, 77 percent of elderly singles had no private pension or annuity income, while just 10 percent had no Social Security income. Private pensions are typically not indexed formally, but only $12 \%$ of elderly singles had 20 percent or more of their income from private pensions (Grad, 1996), and even then some private pensions are partially indexed, if only on an ad hoc basis. 
which violates the transversality condition for utility maximization. ${ }^{11}$ Therefore,

$$
\frac{d w_{t}}{d t}<0 \forall t>\tau \text { as long as } w_{t}>0 .{ }^{12} \text { This is a main implication of the LCH. }
$$

To get an idea of the age at which wealth might begin to decline, suppose that $r=0.03$ and $\rho=0$. In U.S. mortality data, $h_{66} \approx 0.03$ for males and $h_{74} \approx 0.03$ for females. Then consumption will begin to fall at about age 66 for males and age 74 for females, and so wealth should be declining at those ages.

\subsubsection{Effects of Mortality Risk}

Increasing mortality risk will reduce (algebraically) $\frac{d c_{t}}{d t}$ which will, in turn, reduce (algebraically) $\frac{d w_{t}}{d t}$. This can be shown as follows. ${ }^{13}$

Consider two paths of mortality hazard rates $\left\{h_{t}\right\}$ and $\left\{h_{t}^{*}\right\}$ such that $h_{t}^{*}>h_{t}$. Thus $h_{t}^{*}$ can be thought of as the mortality hazard path of someone who is older. Let the optimal consumption path associated with $h_{t}$ be $c_{t}$, and the optimal consumption path associated with $h_{t}^{*}$ be $c_{t}^{*}$. Suppose that $c_{0}=c_{0}^{*}$. Then,

$$
\left.\frac{d c_{t}^{*}}{d t}\right|_{0}<\left.\frac{d c_{t}}{d t}\right|_{0}
$$

because of the higher mortality rish. Therefore, for a time $c_{t}^{*}<c_{t}$ as is shown in Figure 2. Suppose that at some later age, $\tau, c_{t}^{*}=c_{t}$. Then, just as at $t=0$

$$
\left.\frac{d c_{t}^{*}}{d t}\right|_{\tau}<\left.\frac{d c_{t}}{d t}\right|_{\tau}
$$

Because $c_{t}^{*}<c_{t}$ for most of $0<t<T$, w $w_{t}^{*}$, the wealth path associated with $c_{t}^{*}$, would lie above $w_{t}$. Therefore, at $T w_{t}^{*}>0$ which implies that the consumption path is not optimal: the desired consumption path has a negative slope, yet wealth will not decline as long as $c_{t}^{*}<A$. The conclusion is that $c_{0}^{*}>c_{0}$, which implies that

\footnotetext{
${ }^{11}$ In the absence of a bequest motive, all wealth should be consumed by the greatest age possible.

${ }^{12}$ These general result hold for some other annuity paths, ones that are rising for example. If the annuity path falls more rapidly than the desired consumption path, however, wealth will always be held until the maximum age possible.

${ }^{13}$ It is not particularly interesting to analyze what happens when mortality risk increases keeping life expectancy constant because there is no empirical counterpart to this analysis: variations in mortality rates by observable characteristics change life expectancy. This makes the situation quite different from the analysis of asset markets where there is a tradeoff between average return and the variance in return.
} 


$$
\left.\frac{d w_{t}^{*}}{d t}\right|_{0}<\left.\frac{d w_{t}}{d t}\right|_{0} \text { algebraically. }
$$

Thus, if wealth is declining under $h_{t}$, wealth would decline more rapidly under $h_{t}^{*}$. An implication is that cet. par. at greater ages the consumption path will be steeper and the rate of wealth decumulation greater than at younger ages.

2.1.2. Effects of initial wealth.

$$
\begin{aligned}
& \text { From } \frac{d u_{t}}{d t}=u_{t}\left(h_{t}+\rho-r\right) \text { and } \frac{d c_{t}}{d t}=\frac{1}{u_{t t}} u_{t} \\
& \frac{d \ln c_{t}}{d t}=\frac{1}{c_{t}} \frac{u_{t}}{u_{t t}} \theta_{t}=-\frac{1}{\gamma_{t}} \theta_{t}
\end{aligned}
$$

where $\theta_{t}=h_{t}+\rho-\mathrm{r}$, and $\gamma_{t}=-\frac{c_{t} u_{t t}}{u_{t}}$ is a measure of risk aversion evaluated at $c_{t}$. Then

$$
c_{t}=c_{0} e^{-\xi_{t}} \text { where } \xi_{t}=\int_{0}^{t} \frac{1}{\gamma_{t}} \theta_{t} d t
$$

$\xi_{t}$ can be thought of as the average discount rate (including mortality risk) over the period $(0, t)$ adjusted for risk aversion. Then

$$
\frac{d c_{t}}{d w_{0}}=\frac{d c_{0}}{d w_{0}} e^{-\xi_{t}}-c_{0} e^{-\xi_{t}} \frac{d \xi_{t}}{d w_{0}}=\left(\frac{d \ln c_{0}}{d w_{0}}-\frac{d \xi_{t}}{d w_{0}}\right) c_{t}
$$

Differentiating the budget constraint with respect to initial wealth and using $c_{T}=A$ gives

$$
\begin{aligned}
& \int_{0}^{T} \frac{d c_{t}}{d t} e^{-r t} d t=1, \text { or } \\
& \int_{0}^{T}\left[\frac{d l n c_{0}}{d w_{0}}-\frac{d \xi_{t}}{d w_{0}}\right] c_{t} e^{-r t} d t=1, \text { or } \\
& \int_{0}^{T}\left[\frac{d l n c_{0}}{d w_{0}}-\frac{d \xi_{t}}{d w_{0}}\right] c_{t} e^{-r t} d t=1, \text { or } \\
& \frac{d l n c_{0}}{d w_{0}} \int_{0}^{T} c_{t} e^{-r t} d t-\int_{0}^{T} \frac{d \xi_{t}}{d w_{0}} c_{t} e^{-r t} d t=1, \text { or } \\
& \frac{d \ln c_{0}}{d w_{0}}=\frac{1+\int_{0}^{T} \frac{d \xi_{t}}{d w_{0}} c_{t} e^{-r t} d t}{A \delta_{T}+w_{0}}, \text { where } \delta_{T}=\int_{0}^{T} e^{-r t} d t, \text { and using }
\end{aligned}
$$




$$
\int_{0}^{T} c_{t} e^{-r t} d t=\int_{0}^{T} A e^{-r t} d t+w_{0}=A \delta_{T}+w_{0}
$$

In the case of constant relative risk aversion (CRRA)

$$
u=\frac{c^{1-\gamma}}{1-\gamma}
$$

and $\gamma_{t}=\gamma$, so that $\frac{d \xi_{t}}{d w_{0}}=0$. Then

$$
\frac{d \ln c_{0}}{d w_{0}}=\frac{1}{A \delta_{T}+w_{0}}
$$

and the interpretation of $A \delta_{T}+w_{0}$ is discounted expenditures between 0 and $T$. If $A$ is small so that most of resources are from wealth

$$
\frac{d \ln c_{0}}{d \ln w_{0}} \approx 1
$$

In the general case

$$
\frac{d \xi_{t}}{d w_{0}}=\int_{0}^{t}\left(-\frac{\theta_{t}}{\gamma_{t}^{2}} \frac{d \gamma_{t}}{d c_{t}} \frac{d c_{t}}{d w_{0}}\right) d t
$$

In that $\frac{d c_{t}}{d w_{0}}>0, \frac{d \xi_{t}}{d w_{0}}$ will be negative if $\frac{d \gamma_{t}}{d c_{t}}$ is positive, that is, relative risk aversion increases as consumption increases (IRRA). Then the response of $l n c_{0}$ to $w_{0}$ would be reduced relative to the CRRA case. Take $c_{0}$ to be a function of $w_{0}$, and then integrate from $w_{0}=0$ to $w_{0}$ :

$$
c_{0}=A e^{\int \frac{d \ln c_{0}}{d w_{0}} d w_{0}}
$$

where the constant of integration comes from the fact that $c_{0}=A$ when $w_{0}=0$. Therefore, under IRRA, $c_{0}$ will be less than it would be under CRRA. The is illustrated in Figure 3a. Relative to CRRA, the consumption path will be flatter at high levels of consumption and steeper at low levels of consumption because

$$
\frac{d \ln c_{t}}{d t}=-\frac{1}{\gamma_{t}} \theta_{t}
$$

For the same initial wealth level, this will require that initial consumption will be lower.

To see how this affects saving, let 


$$
\dot{w}_{t}=\frac{1}{w_{t}} \frac{d w_{t}}{d t}=r-\frac{c}{w_{t}}+\frac{A}{w_{t}}
$$

and $\frac{d \dot{w}_{0}}{d w_{0}}$ is the change in the initial rate of saving for a change in initial wealth.

$$
\begin{aligned}
& \frac{d \dot{u}_{0}}{d w_{0}}=-\frac{1}{w_{0}} \frac{d c_{0}}{d w_{0}}+\frac{c_{0}-A}{w_{0}^{2}} \\
& =-\frac{c_{0}}{w_{0}} \frac{d l n c_{0}}{d w_{0}}+\frac{c_{0}-A}{w_{0}^{2}} \\
& =\frac{1}{w_{0}^{2}} \frac{A\left(\delta_{T} c_{0}-A \delta_{T}-w_{0}\right)-c_{0} w_{0} \int_{0}^{T} \frac{d \xi_{t}}{d w_{0}} c_{t} e^{-r t} d t}{A \delta_{T}+w_{0}} \text { after some manipulation. }
\end{aligned}
$$

If consumption is declining, which is a sufficient condition for wealth to decline, the first term in the numerator is positive:

$$
\int_{0}^{T} c_{0} e^{-r t} d t-A \delta_{T}-w_{0}>\int_{0}^{T} c_{t} e^{-r t} d t-A \delta_{T}-w_{0}=0
$$

Thus, under CRRA, $\frac{d \dot{w}_{0}}{d w_{0}}$ will be positive and an increase in bequeathable wealth will cause the rate of saving to increase: if an individual is dissaving, an increase in wealth will reduce the rate of dissaving and the wealth path will be flattened.

In the general case, however, a sufficient condition for $\frac{d \dot{w}_{0}}{d w_{0}}$ to be positive is that

$$
\int_{0}^{T} \frac{d \xi_{t}}{d w_{0}} c_{t} e^{-r t} d t<0
$$

As we have seen this will happen if $\frac{d \gamma_{t}}{d c_{t}}$ is positive. Then the wealth path would be flattened even further relative to CRRA.

If $\frac{d \gamma_{t}}{d c_{t}}$ is negative, $\frac{d \dot{w}_{0}}{d w_{0}}$ could be negative, so that an increase in initial wealth could case the rate of dissaving to increase. To see how this could happen consider the somewhat artificial example illustrated in Figure $3 \mathrm{~b}$. Let $r=0$, and suppose that $u_{t} a_{t} e^{-\rho t} \geq d_{2}, t \leq T$ and that $T \times c^{*}=w_{0}$. Then initially the consumption path would be flat at $c^{*}$ until $T$ when it would drop to $A$. Now suppose that wealth is increased slightly but that because of the shape of the survival curve and discounting, $u_{t} a_{t} e^{-\rho t}<d_{2}, t>T$. Then the additional wealth would be entirely allocated to consuming initially at $\widetilde{c}$ until all additional wealth is consumed. If $\frac{c_{0}-A}{w_{0}}$ is small and $\widetilde{c}-c^{*}$ is large,

$$
\frac{d \dot{w}_{0}}{d w_{0}}=-\frac{1}{w_{0}} \frac{d c_{0}}{d w_{0}}+\frac{c_{0}-A}{w_{0}^{2}}
$$


could be made to be negative. That is, an increase in initial wealth would cause the rate of dissaving to increase.

\subsubsection{Effects of the annuity stream.}

An increase in Social Security could either increase or decrease $T$, and the effects on the rate of wealth change will differ. Consider first a utility function such that an increase in Social Security causes $T$ to decline. Then, as shown in Figure $3 c$, the new consumption path, $c_{t}^{*}$, must be everywhere above the old consumption path, $c_{t}$, because consumption paths cannot cross: were they to cross the equation of motion of marginal utility will require that the marginal utilities be the same both before and after that point. That is, the paths would be the same. But if bequeathable wealth is to be exhausted both at $T$ and at $T^{*}$ the consumption path $\left\{c^{*}\right\}$ must lie above $\{c\}$.

The path of bequeathable wealth depends on the utility function; but because $T^{*}<T, w^{*}$ will be less than $w$ over at least one part of the interval $\left(0, T^{*}\right)$. If the interval is the entire age range $\left(0, T^{*}\right),\left\{w^{*}\right\}<\{w\}$ and

$$
\left.\frac{d w_{t}^{*}}{d t}\right|_{0}<\left.\frac{d w_{t}}{d t}\right|_{0}
$$

As shown in Figure 4, the interval over which $w^{*}<w$ could be less than the entire age range. At some age, say $\tau, w_{\tau}^{*}=w_{\tau}$. Now consider a different person with initial age of $\tau$ and initial wealth of $w_{\tau}^{*}$. This person would have a wealth path such that $\left\{w^{*}\right\}<\{w\}$. Therefore, for this person an increase in Social Security benefits would initially cause a higher rate of wealth decumulation.

We see from this example that increasing Social Security benefits can cause $\frac{d w_{t}}{d t}$ to decrease. However, this result is not general because the sign of $\frac{d T}{d A}$ depends on the particular form of the instantaneous utility function. I demonstrate this by giving two examples: the first is a simple utility function in which I show graphically that $\frac{d T}{d A}$ is positive; the second is the constant relative risk utility function for which I show analytically that $\frac{d T}{d A}$ is negative.

First, consider the utility function $u^{*}$ :

$$
u^{*}(c)=\left\{\begin{array}{l}
c, c \leq \alpha \\
\alpha, c>\alpha
\end{array}\right.
$$

$u^{*}$ and $\tilde{u}$, another utility function to be discussed below, are illustrated in Figure 5. Let 
$A<\alpha,\left(h_{t}+\rho\right)=\lambda$, a constant, and $r=0$. The utility maximizing consumption path is

$$
c_{t}=\left\{\begin{array}{l}
\alpha, t<T \\
A, t \geq T
\end{array}\right.
$$

The path is illustrated in Figure 6. Let initial bequeathable wealth be $w_{0}$. Then, $T$ is given by $(\alpha-A) T=w_{0} \cdot \frac{d T}{d w_{0}}=\frac{1}{\alpha-A}>0$, and

$$
\frac{d T}{d A}=\frac{w_{0}}{(\alpha-A)^{2}}>0
$$

That is, increasing Social Security benefits increases $T$. Over an interval, therefore, $w^{*}>w$, and an increase in Social Security would increase $\frac{d w_{t}}{d t}$ algebraically. Of course, in this particular example,

$$
\left.\frac{d\left(d w_{t} / d t\right)}{d A}\right|_{t=0}=1 \text { as can be calculated directly. }
$$

This utility function does not satisfy the strict concavity assumption. But, as illustrated in Figure 5, a slightly modified utility function, $\tilde{u}$, would satisfy strict concavity, and it would lead to the same qualitative result.

In the second example I take the utility function to be $e^{14}$

$$
u(c)=\frac{c^{1-\gamma}}{1-\gamma}
$$

The optimal consumption trajectory is given by

$$
\begin{aligned}
& c_{t}^{-\gamma}=A^{-\gamma} \frac{a_{T}}{a_{t}} e^{(r-\rho)(T-t)} \text { for } t<T \text { and } \\
& w_{t}=w_{0} e^{r t}+\int_{0}^{t}\left(A-c_{s}\right) e^{r(t-s)} d s, \text { the budget constraint, with } \\
& w_{0} \text { given } \\
& w_{T}=0, \text { and } \\
& c_{t}=A, t \geq T
\end{aligned}
$$

The consumption path implies that

\footnotetext{
${ }^{14}$ This is the case considered by Bernheim, 1987.
} 


$$
\frac{d c_{t}}{d A}=c_{t}\left(\frac{1}{A}+\theta_{T} \frac{d T}{d A}\right)
$$

in which $\theta_{T}=\frac{1}{\gamma}\left(h_{T}+\rho-r\right)$. Differentiating the budget constraint with respect to $A$, and using the fact that $C_{T}=A$, gives

$$
\begin{aligned}
\int_{0}^{T} e^{-r t} & =\int_{0}^{T} \frac{d c_{t}}{d A} e^{-r t} d t \\
& =\left(\frac{1}{A}+\theta \frac{d T}{T d A}\right) \int_{0}^{T} c_{t} e^{-r t} d t \\
& =\left(\frac{1}{A}+\theta \frac{d T}{T d A}\right)\left(w_{0}+A \int_{0}^{T} e^{-r t} d t\right) .
\end{aligned}
$$

Thus

$$
\frac{\delta_{T}}{w_{0}+A \delta_{T}}=\frac{1}{A}+\theta_{T} \frac{d T}{d A}
$$

where $\delta_{T}=\int_{0}^{T} e^{-r t} d t$. Then

$$
\frac{d T}{d A}=-\frac{w_{0}}{\theta_{T}\left(w_{0}-1+A^{2} \delta_{T}\right)}
$$

Because $\theta_{T}$ and $\delta_{T}$ are positive, $\frac{d T}{d A}$ is negative. ${ }^{15}$ Therefore, with this utility function, increasing $A$ could cause the average rate of wealth change over the interval $(0, T)$ to decrease algebraically, so that if wealth is declining the rate of decumulation could increase.

However, for empirical work one would like to relate the rate of dissaving at any time to levels of annuities. That is, we need the relationship between $\frac{d \dot{w}_{t}}{d A}$ and $A$. From (3) and (4)

$$
\begin{gathered}
\frac{d c_{t}}{d A}=c_{t}\left[\frac{1}{A}-\theta_{T} \frac{w_{0}}{\theta_{T}\left(w_{0} A+A^{2} \delta_{T}\right)}\right] \\
=\frac{c_{t}}{A}\left[1-\frac{w_{0}}{w_{0}+A \delta_{T}}\right]
\end{gathered}
$$

$A \delta_{T}$ is total annuity income over the period 0 to $T$, so that $\frac{w_{0}}{w_{0}+A \delta_{T}}$

has the interpretation of the fraction of resources over the period that comes from initial ${ }^{15} \mathrm{~A}$ condition for global utility maximization is that $\theta_{T}=\frac{1}{\gamma}\left(h_{t}+\rho-r\right)>0$. 
bequeathable wealth. This also shows that

$$
0<\frac{d \ln c_{0}}{d \ln A}<1
$$

The rate of wealth change is $\frac{d w_{t}}{d t}=r w_{t}-c_{t}+A_{t}$, so

$$
\begin{aligned}
\frac{d(d w / d t)}{d A} & =-\frac{d c}{d A}+1 \\
& =-\frac{c_{0}}{A}\left(1-\frac{w_{0}}{w_{0}+A \delta_{T}}\right)+1 \\
& =-\frac{c_{0}}{A}\left(\frac{A \delta_{T}}{w_{0}+A \delta_{T}}\right)+1 .
\end{aligned}
$$

The first term is the product of two factors, the first of which is greater than one if wealth is falling, and the second is less than one. If the consumption path, which follows the survivor curve, has a long tail, so that $\frac{A \delta_{T}}{w_{0}+A \delta_{T}}$ is large, the first term will tend to be large and an increase in annuities will cause the rate of dissaving to increase. If the consumption path is rather flat but then declines sharply so that $\frac{A \delta_{T}}{w_{0}+A \delta_{T}}$ is small, the rate of dissaving will decrease. Bernheim found $\frac{d(d w / d t)}{d A}$ to be negative, apparently the result of his assumption that mortality risk is constant, which implies that the rate of change of consumption is constant.

These results also show that under some circumstances an increase in Social Security would cause bequests to fall: Suppose that over the entire age range $\left(0, T^{*}\right)$, $\left\{w^{*}\right\}<\{w\}$. Then

$$
\int_{0}^{N} w_{t}^{*} m_{t} e^{-\rho t} d t<\int_{0}^{N} w_{t} m_{t} e^{-\rho t} d t
$$

where $m_{t}$ is the path of mortality probabilities. The left-hand side is expected discounted bequests with the wealth path $w^{*}$ and the right-hand side is expected discounted bequests with the wealth path $w$. Thus, an increase in Social Security benefits would decrease expected bequests. ${ }^{16}$

2.2 Bequest motive: $V_{t}>0$

With a bequest motive the equation of motion of marginal utility is

\footnotetext{
${ }^{16}$ See Hurd, 1993 for an empirical estimate of, the effect.
} 


$$
\frac{d u_{t}}{d t}=u_{t}\left(h_{t}+\rho-r\right)-h_{t} V_{t} \quad \text { for } w_{t}>0
$$

For a fixed level of consumption (and, therefore, $u_{t}$ ) a bequest motive reduces $\frac{d u_{t}}{d t}$, and increases the slope of the consumption path:

$$
\left.\frac{d c_{t}}{d t}\right|_{V_{t}>0}>\left.\frac{d c_{t}}{d t}\right|_{V_{t}=0}
$$

Thus if consumption is declining a bequest motive will flatten the consumption path.

Over an interval $(0, t)$ where $w_{t}>0$

$$
u_{0}=u_{t} a_{t} e^{(r-\rho) t}+\int_{0}^{t} V_{s} e^{(r-\rho) s} m_{s} d s
$$

This equation says to allocate consumption between time 0 and time $t$ in such a way that the utility loss is balanced by the discounted expected utility gain from consumption at $t$ plus the discounted increase in expected utility from bequests. A bequest motive will cause wealth decline more slowly; that is, more wealth will be held. This can be shown as follows.

Let $u_{t}(1)$ be marginal utility when there is a bequest motive and $u_{t}(0)$ be marginal utility when there is none. Similarly for $c_{t}(1)$ and $c_{t}(0)$, and $w_{t}(1)$ and $v_{t}(0)$. Let $\left\{c_{t}(0)\right\}$ be the optimal consumption path of someone without a bequest motive and suppose that at some $T, w_{T}(0)=0$. $T$ could be $N$, the maximum age possible.

Let initial wealth be the same: $w_{0}(1)=w_{0}(0)$. If initially consumption is chosen to be the same,

$$
\frac{d u_{t}(1)}{d t}<\frac{d u_{t}(0)}{d t}
$$

which implies that

$$
\frac{d c_{t}(1)}{d t}>\frac{d c_{t}(0)}{d t}
$$

Thus initially $c_{t}(1)>c_{t}(0)$

But then $c_{t}(1) \geq c_{t}(0) \forall t$ : if they are the same at, say, $\tau$,

$$
\left.\frac{d c_{t}(1)}{d t}\right|_{\tau}>\left.\frac{d c_{t}(0)}{d t}\right|_{\tau}
$$


and $c_{t}(1)$ would remain greater than $c_{t}(0)$ as shown in Figure $T$.

Therefore, $w_{t}(1)<w_{t}(0) \forall t$. But $w_{T}(0)=0 \Rightarrow w_{T}(1)<0$, which violates the nonnegativity restriction. The conclusion is that $c_{0}(1)$ must be chosen to be less than $c_{0}(0)$ which implies that

$$
\left.\frac{d w_{t}(1)}{d t}\right|_{0}>\left.\frac{d w_{t}(0)}{d t}\right|_{0}
$$

That is, a bequest motive causes wealth to decline more slowly

This kind of result holds more generally under uncertainty, provided the distribution of random events is the same for those with and without a bequest motive (Hurd, 1987).

\section{Utility maximization by Couples}

The model for couples is similar to the model for singles: couples have a utility function defined over consumption while both spouses are alive, and they get utility from contemplating "bequests." However, there are two types of bequests: wealth to a surviving spouse, and wealth to a third person at the death of the surviving spouse. ${ }^{17}$ In this situation couples will choose a consumption path $\left\{C_{t}\right\}$ to maximize ${ }^{18}$

$$
\int_{0} U\left(C_{t}\right) e^{-\rho t} a_{t} d t+\int_{0} M\left(w_{t}\right) e^{-\rho t} p_{m_{t}} d t+\int_{0} F\left(w_{t}\right) e^{-\rho t} p_{f_{t}} d t+\int_{0} V\left(w_{t}\right) e^{-\rho t} m_{t} d t
$$

$U(\cdot)=$ utility function of the couple

$\rho=$ subjective discount rate of the couple

$a_{t}=$ probability that both spouses will be alive at $t$.

$M(\cdot)=$ widower's utility of wealth

$p_{m_{t}}=$ probability (density) that the husband becomes a widower at $t$; that is, the probability that the wife dies at $t$ and the husband is still alive at $t$.

$F(\cdot)=$ widow's utility of wealth

$p_{f_{t}}=$ probability (density) that the wife becomes a widow at $t$.

$V(\cdot)=$ utility from true bequests (bequeathed outside the household)

$w_{t}=$ bequeathable wealth at $t$

${ }^{17}$ In this model all of the wealth of the couple is transferred to the surviving spouse at the death of one spouse. It is only at the death of the second spouse that wealth is inherited by children or others.

${ }^{18}$ See Hurd, 1992a. 
$m_{t}=$ the probability (density) that the surviving spouse dies at $t$.

This objective function has the same structure as in the single's problem: the couple gets utility from consumption and utility from "bequests." The utility from bequests is in three parts: future utility of the widower, future utility of the widow, and future utility from a true bequest.

The maximization is subject to

$$
\begin{aligned}
& \frac{d w_{t}}{d t}=r w_{t}-C_{t}+A_{t} \\
& r=\text { the real rate of interest (fixed and known); } \\
& A_{t}=\text { annuities, including Social Security and other pensions; } \\
& w_{0} \text { is given; and } \\
& w_{t} \geq 0 .
\end{aligned}
$$

The solution is

$$
\frac{d U_{t}}{d t}=U_{t}\left(h_{t}+\rho-r\right)-\left(M_{t} \dot{\phi}_{t}+F_{t} \mu_{t}\right)
$$

$U_{t}=$ marginal utility of consumption by the couple

$h_{t}=$ the couple's mortality risk (the probability density that one of them will die at $t$ given that neither has died before $t$ )

$M_{t}=$ widower's marginal utility of wealth

$F_{t}=$ widow's marginal utility of wealth

$\phi_{t}=$ mortality risk of the wife (the probability density that the wife will die at $t$ given that she has survived to $t$ )

$\mu_{t}=$ mortality risk of the husband

The solution has the same structure as the solution to the single's problem with the last term in (5) corresponding to the last term in (2). In the case of the couple the wealth goes to the surviving spouse; in the case of the single person the wealth goes to the heir.

The marginal utility of true bequests does not appear in the solution because the probability that both spouses die in a short period is zero. The bequest motive acts through the marginal utility of wealth of the widow or widower.

Because of time separability of utility, the couple maximizes utility starting from any arbitrary date. That is, as long as the couple is alive, we can put $t=0$ and solve 
the utility maximization problem forward from that date.

At a later time $t$ either both spouses are alive, the husband only is alive, the wife only is alive, or both have died, so the probabilities of these outcomes must sum to 1 . That is,

$$
a_{t}=1-b_{t}-f_{t}-\int_{0}^{t} m_{s} d s
$$

where $b_{t}=$ probability that the widower only is alive at $t$, and $f_{t}=$ probability that the widow only is alive at $t$. If $t$ becomes small the probability that both will die between 0 and $t$ goes to zero. Therefore, in a small interval of time a bequest takes place through the surviving spouse, not through the simultaneous deaths of both spouses: one spouse must die in order that the probability the other spouse will die and leave a bequest becomes positive. Typical trajectories of the probabilities $a_{t}, b_{t}, f_{t}$ and the density $m_{t}$ are shown in Figure 8.

The relationship between $h_{t}, \phi_{t}$ and $\mu_{t}$ can be found as follows. Let $h_{t 0}$ be the probability density that one spouse or the other or both die at $t$ given that both are alive at $t=0$.

and

$$
a_{t}=1-\int_{0}^{t} h_{s 0} d s
$$

$$
h_{t 0}=-\frac{d a_{t}}{d t}=\frac{d b_{t}}{d t}+\frac{d f_{t}}{d t}+m_{t}
$$

Let $\phi_{t 0}$ be the mortality probability density of all females alive at $t=0$, and $\mu_{t 0}$ the mortality probability density of males.

Under the assumption that the mortality outcomes of the husband and the wife are independent, the probability that the husband only is alive at $t$ is given by

$$
b_{t}=\int_{0}^{t} \phi_{s 0} d s\left[1-\int_{0}^{t} \mu_{s 0} d s\right]
$$

Similarly,

$$
f_{t}=\int_{0}^{t} \mu_{s 0} d s\left[1-\int_{0}^{t} \phi_{s 0} d s\right]
$$

Then,

$$
\frac{d b t}{d t}=\phi_{t 0}\left[1-\int_{0}^{t} \mu_{s 0} d s\right]-\mu_{t 0} \int_{0}^{t} \phi_{s 0} d s \rightarrow \phi_{0} \text { as } t \rightarrow 0
$$


This says that the rate of flow of husbands to widowers is given by the mortality risk of wives.

In a similarly way

$$
\frac{d f_{t}}{d t} \rightarrow \mu_{0}
$$

Then,

$$
m_{t}=\mu_{t} b_{t}+\phi_{t} f_{t} \rightarrow 0 \text { as } t \rightarrow 0 \text { because } b_{t} \text { and } f_{t} \rightarrow 0 .
$$

Finally, $h_{t 0} \rightarrow \phi_{0}+\mu_{0}$ as $t \rightarrow 0$. This holds at any $t$ so that $h_{t}=\phi_{t}+\mu_{t}$. That is, the mortality risk of the couple is the sum of the mortality risks of each spouse. ${ }^{19}$

In (5), $h_{t}+\rho$ will be larger than $r$ if the couple is sufficiently old because both $\phi_{t}$ and $\mu_{t}$ increase approximately exponentially. Therefore, in the absence of the second term in (5), $U_{t}$ would increase. The second term flattens the path of $U_{t}$ and could even cause it to fall. Thus, with the usual assumption that $U(\cdot)$ is concave, the second term flattens the path of consumption, which would otherwise be declining, and could even cause the path to rise. This "bequest" motive (to leave wealth to the surviving spouse) has the same effect on the consumption path of a couple as it does on the consumption path of a single person. Beyond the fact that the consumption path is flattened, the path of marginal utility is not easy to analyze because neither $M_{t}$ nor $F_{t}$ could be expected to be constant as bequeathable wealth varies.

\subsection{No true bequest motive.}

In the absence of a bequest motive, a terminal condition is that $w_{t}$ must go to zero at the greatest age to which the household could survive. Further, if one spouse is very old (say the husband), and approaches the greatest age to which that spouse could possibly live, the couple should decumulate wealth provided the younger spouse is not too young. This can be seen as follows.

If $N$ is the maximum age to which the husband can live, a condition for utility maximization by the couple is that $U_{t} \approx F_{t}$ as $t \rightarrow N$. (This will be shown section 3.2 ). Also, $M_{t} \rightarrow 0$ as $t \rightarrow N$ : should the wife die, wealth is worth little to the widower because with increasing mortality risk, the flow of consumption will increase reducing the marginal utility of consumption and of wealth to zero. Then,

${ }^{19}$ This would hold with assortative mating (where long-lived men tend to marry long-lived women). The estimation problem would be to find empirical counterparts to the individual mortality risks, as they could not be taken from a life table. 


$$
\begin{aligned}
\frac{d U_{t}}{d t} & =U_{t}\left(h_{t}+\rho-r\right)-\left(M_{t} \phi_{t}+F_{t} \mu_{t}\right) \\
& =U_{t}\left(\phi_{t}+\mu_{t}+\rho-r\right)-\left(M_{t} \phi_{t}+F_{t} \mu_{t}\right) \\
& =U_{t}\left(\phi_{t}+\rho-r\right)+\mu_{t}\left(U_{t}-F_{t}\right)-M_{t} \phi_{t} \\
& \approx U_{t}\left(\phi_{t}+\rho-r\right),
\end{aligned}
$$

as in the singles problem. If $\phi_{t}$, the mortality risk of the wife, is greater than $\rho-r, U_{t}$ will increase and $C_{t}$ will decline. Therefore, wealth will decline: the analysis is the same as in the single's problem.

The conclusion is that the wealth path depends on ages of both husband and wife. If the husband is very old and the wife is not too young (say, older than 74 , as was given in the example for singles) wealth should decline in the absence of a bequest motive. Further, as the analysis of the single's problem showed, the rate of wealth decline will be greater when the wife is older. In this sense, the rate of wealth decumulation is greater among older couples.

When both spouses are retired but have many more years to live, the path of marginal utility depends on the economic circumstances of each should the other die, in particular a comparison of the marginal utility of consumption by the couple with the marginal utility of wealth of each survivor:

$$
\frac{d U_{t}}{d t}=\left(U_{t}-M_{t}\right) \phi_{t}+\left(U_{t}-F_{t}\right) \mu_{t}+U_{t}(\rho-r)
$$

Apparently, wealth could decline at earlier ages than in the example.

The equation of motion of marginal utility (5) can be integrated over a small interval $(0, t)$ to give

$$
U_{0} \approx U_{t} a_{t} e^{(r-\rho) t}+\int_{0}^{t} M_{s} \phi_{s 0} e^{(r-\rho) s} d s+\int_{0}^{t} F_{s} \mu_{s 0} e^{(r-\rho) s} d s
$$

where $\phi_{s 0}$ is the mortality probability density of women alive at 0 and $\mu_{s t}$ is the mortality probability density of men alive at 0 . The interpretation of this equation is that the reallocation of consumption from $t=0$ to $t$ will result in a loss of utility at $t=0$ of $U_{0}$; the offsetting gain is composed of three parts: the discounted increase in utility should the couple live, the discounted increase in utility should the wife die 
between 0 and $t$, and the discounted increase in utility should the husband die between 0 and $t$. The approximation ignores a second-order term which is the utility from true bequests should both spouses die between 0 and $t$, but this term goes to zero as $t$ goes to zero much faster than the other three terms because the probability density goes to zero. Thus, the first-order conditions imply an Euler condition: marginal utility at $t=0$ equals the expected discounted marginal utility in all future periods.

The solution (6) is similar to the solution to the single's problem:

$$
u_{0}=u_{t} a_{t} e^{(r-\rho) t}+\int_{0}^{t} V_{s} e^{(r-\rho) s} m_{s 0} d s
$$

In both cases the path of marginal utility is altered by the expected utility from "bequests."

\subsection{Effect of a true bequest motive:}

The true bequest motive (bequeathing to heirs outside of the household) operates through $M_{s}$ and $F_{s}$ : a bequest motive will increase the marginal utility of wealth of both the widower and the widow. This increases the right-hand side of $(6)$ which requires that $U_{0}$ be increased. That, in turn, requires that $C_{0}$ be decreased with the result that more wealth will be held. Thus, the effect of a true bequest motive is to reduce consumption which will eventually lead to higher wealth. This is shown formally as follows.

In the single's problem, a bequest motive reduced consumption which caused the marginal utility of consumption to increase. A condition for utility maximization by singles is that the marginal utility of consumption equals the marginal utility of wealth. Thus, $M_{t}\left(V_{t}>0\right)>M_{t}\left(V_{t}=0\right)$ holding wealth constant, and the same for $F_{t}$. Since

$$
\frac{d U_{t}}{d t}=U_{t}\left(h_{t}+\rho-r\right)-\left(M_{t} \phi_{t}+F_{t} \mu_{t}\right)
$$

cet. par.

$$
\left.\frac{d U_{t}}{d t}\right|_{V_{t}>0}<\left.\frac{d U_{t}}{d t}\right|_{V_{t}=0}
$$

which implies that

$$
\left.\frac{d C_{t}}{d t}\right|_{V_{t}>0}>\left.\frac{d C_{t}}{d t}\right|_{V_{t}=0}
$$


Thus, if consumption is declining, a bequest motive will flatten the consumption path. This is a main implication of $\mathrm{LCH}$ extended to include a bequest motive.

It seems natural to suppose that a bequest motive will cause more wealth to be held; that is, it will reduce the rate of wealth decumulation, and, indeed, that is the case. To show the result, however, requires that a bequest motive reduces the level of consumption, not the slope of the consumption path, and the level depends on the global survival curve, not just instantaneous mortality risk. This involve an argument along the same lines as the argument for the single's model, but which is more involved.

Let $N$ be the maximum age to which the husband can live and $P$ be the maximum age to which the wife can live. To simplify the discussion let $P>N .{ }^{20}$ Let $\phi_{t} M_{t}+\mu_{t} F_{t}=\Omega_{t}$, the expected marginal utility of wealth. $M_{t}$ and $F_{t}$ are the margina: utilities of wealth of survivors, and they depend on wealth, the annuity path of the survivor and the path of mortality rish of the survivor. The are calculated by solving the single's problem. Let $\Omega_{t}(1, w)$ indicate marginal utility when there is a bequest motive and $\Omega_{t}(0, w)$ indicate no bequest motive. As shown in section $2, \Omega_{t}$ has the properties:

1. $\Omega_{t}(1, w)>\Omega_{t}(0, w)$ : the expected marginal utility of wealth of the
survivors is greater with a bequest motive than without. This follows because in the single's problem, initial consumption is smaller when there is a bequest motive, and lower consumption implies higher marginal utility of consumption.

2. $\Omega_{t}(j, w)>\Omega_{t}(j, w+\delta), \delta>0, j=0,1$ : the expected marginal utility 0 : wealth decreases in wealth. In the singles problem increasing wealth increases consumption, which decreases the marginal utility of consumption (which equals the marginal utility of wealth).

The first-order conditions of the couple's problem includes

$$
\frac{d U_{t}}{d t}=U_{t}\left(h_{t}+\rho-r\right)-\Omega_{t}
$$

Let $T$ be the wife's age at which bequeathable wealth is exhausted when there is no bequest motive. There are two cases: $T<N$ and $T \geq N$. The simplest is when $T<:$ because the argument follows the same line as for the single's problem, so consider fir: that case.

We want to show that $C_{0}(1)<C_{0}(0)$. Suppose instead that $C_{0}(1)=C_{0}(0) .{ }^{21}$

${ }^{20}$ It will be apparent that the argument holds for $P<N$.

${ }^{21}$ It will be clear that the argument holds a fortiori for $C_{0}(1)>C_{0}(0)$. 
Then

$$
\left.\frac{d U_{t}(1)}{d t}\right|_{0}<\left.\frac{d U_{t}(0)}{d t}\right|_{0}
$$

because $\Omega_{0}(1)>\Omega_{0}(0)$. Therefore,

$$
\left.\frac{d C_{t}(1)}{d t}\right|_{0}>\left.\frac{d C_{t}(0)}{d t}\right|_{0}
$$

For small $t, C_{t}(1)>C_{t}(0)$, which implies that

$$
\left.\frac{d w_{0}(1)}{d t}\right|_{0}<\left.\frac{d w_{0}(0)}{d t}\right|_{0} \text { and } w_{t}(1)<w_{t}(0) \text {. }
$$

The situation is illustrated in Figure $9 .{ }^{22}$

For a time, $C_{t}(1)>C_{t}(0)$ and $w_{t}(1)<w_{t}(0)$. Suppose that eventually at time $\tau, C_{\tau}(1)=C_{\tau}(0)$. But $\Omega_{\tau}\left(1, w_{\tau}(1)\right)>\Omega_{\tau}\left(0, w_{\tau}(0)\right)$ both because of the bequest motive and because $w_{\tau}(1)<w_{\tau}(0)$. Therefore,

$$
\left.\frac{d C_{t}(1)}{d t}\right|_{\tau}>\left.\frac{d C_{t}(0)}{d t}\right|_{\tau}
$$

and $C_{t}(1)$ will once again become greater than $C_{t}(0)$. This implies that $C_{t}(1) \geq C_{t}(0)$ $\forall t$. In that $w_{t}(1)<w_{t}(0)$ and $w_{T}(0)=0, w_{t}(1)$ will become negative for some $t<T$, which violates the borrowing constraint. The conclusion is that $C_{0}(1)<C_{0}(0)$ which implies that

$$
\left.\frac{d w_{0}(1)}{d t}\right|_{0}>\left.\frac{d w_{0}(0)}{d t}\right|_{0}
$$

That is, wealth declines more slowly with a bequest motive than without.

If $T>N$ and $C_{0}(1)=C_{0}(0), C_{t}(1) \geq C_{t}(0) \forall t \leq N$ and $w_{N}(1)<w_{N}(0)$ by the argument just given. Should the husband live to $N$, he will die with probability one and the wife will change to the consumption path given by the solution to the single's problem as shown in Figure 10. Let $c_{t}$ be the consumption by the widow. Suppose that $c_{N}(1) \geq c_{N}(0)$. Then the wealth condition on $w_{t}(1)$ will be violated: $w_{N}(1)<w_{N}(0)$, yet $c_{t}(1)>c_{t}(0), t>N$, by the same reasoning as in the single's problem, and, therefore, $w_{t}(1)<w_{t}(0), t>N$. The path $c_{t}(1)$ cannot be optimal because wealth would be exhausted before $T$. The argument is the same as in the single's problem.

${ }^{22}$ The figure also shows the change in the annuity stream at the death of the husband $(N)$. This is typical under Social Security law. 
If, however, $c_{t}(1)<c_{t}(0), t>N$, the lifetime budget constraint could be satisfied, and $w_{T^{*}}(1)=0$ and $c_{t}(1)=A, t \geq T^{*}$ which are two necessary global conditions for utility maximization. Whether this could happen depends on whether the two consumption levels $C_{N}(1)$ and $c_{N}(1)$ satisfy optimality conditions which relate the marginal utility of consumption by the couple, $U_{N}$, to the marginal utility of wealth of the widow, $F_{N}$.

The relationship between the marginal utility of consumption by the couple and the marginal utility of wealth of the widow is found from

$$
U_{t} \approx U_{N}{ }_{N} e^{(r-\rho)(N-T)}+\int_{t}^{N} M_{s} \phi_{s} e^{\left(r-\rho_{m}\right) s} d s+\int_{t}^{N} F_{s} \mu_{s} e^{\left(r-\rho_{f}\right) s} d s
$$

As $t \rightarrow N$, the relationship becomes exact. As $t \rightarrow N, a_{t} \rightarrow 0$ because the husband will die with probability 1 by $N$. Further, $M_{s} \rightarrow V_{N}$ as $t \rightarrow N$ : as the mortality risk of the husband becomes large the marginal utility of consumption by him should his wife die goes to zero in that his mortality risk becomes large. Then wealth only has value in the interval $(t, N)$ as $t \rightarrow N$ as a true bequest, and its value is $V_{N}$. $\phi_{s t}$ is the probability density that the wife will die at $s$ given that she is alive at $t$, and $\int_{t}^{N} \phi_{s t} d t \rightarrow 0$ as $t \rightarrow N$; that is, the probability that she will die in the interval goes to zero because the wife has positive probability of living past $N$. Thus $\int_{t}^{N} \dot{\phi}_{s t} e^{(r-\rho) s} d t \rightarrow 0$, and

$$
\int_{t}^{N} M_{s} \phi_{s t} e^{(r-\rho) s} d s \rightarrow 0 \text { as } t \rightarrow N
$$

Because the probability the husband will die in the interval equals 1 , and $\mu_{s t}$ is the probability (density) that the husband dies at $s$ given that he lives to $t$,

$$
\int_{t}^{N} \mu_{s t} d s=1, \text { and } \int_{t}^{N} \mu_{s} e^{\left(r-\rho_{f}\right) s} d s \rightarrow 1 \text { as } t \rightarrow N .
$$

Thus

$$
\int_{t}^{N} F_{s} \mu_{s} e^{\left(r-\rho_{f}\right) s} d s \rightarrow F_{N} \text { as } t \rightarrow N
$$

and

$$
U_{t} \rightarrow F_{N} \text { as } t \rightarrow N \text {. }
$$

That is, as $t \rightarrow N$, the marginal utility of consumption by the couple converges to the 
marginal utility of wealth of the widow. If $c_{N}$ is consumption by the widow and $u_{N}$ is marginal utility of consumption by the widow, $u_{N}=F_{N}$ and because of returns to scale in consumption I imagine that $c_{N}<C_{N}$ (although this last is not important for the argument).

If $c_{N}(1)<c_{N}(0)$ the wealth condition will not necessarily be violated (Figure 9). But then

$$
U_{N}(1) \leq U_{N}(0)=u_{N}(0)<u_{N}(1)
$$

The first weak inequality results from $C_{N}(1) \geq C_{N}(0)$ and the inequality results from $c_{N}(1)<c_{N}(0)$. But a condition for utility maximization by the couple with a bequest motive is that

$$
U_{N}(1)=F_{N}(1)=u_{N}(1)
$$

Thus, the couple with a bequest motive should choose its consumption at $N$ to be less than $C_{N}(0)$. This will reduce consumption at all previous periods, including $C_{0}$, and, in fact, will require that

$$
C_{0}(1)<C_{0}(0)
$$

The conclusion is that

$$
\left.\frac{d w_{0}(1)}{d t}\right|_{0}>\left.\frac{d w_{0}(0)}{d t}\right|_{0}
$$

That is, cet. par., the wealth of a couple with a bequest motive will decline more slowly than the wealth of a couple without a bequest motive.

\section{Effect of marital status}

The rate of wealth decumulation by couples will differ from that of singles because of differences in mortality risk, differences in their utility functions, and because of differences in their resources. To make a meaningful comparison, I will make simplifying assumptions that hold constant mortality risk and preferences. There is no obvious best way to control for economic resources, so I will give two examples based on 
quite different assumptions.

\subsection{Households have same resources.}

I will compare a couple with a single person, and assume that each household has the same bequeathable wealth and the same real constant annuity stream, and that the annuity stream will not change at the death of one of the spouses. ${ }^{23}$ Each spouse has the same (unisex) life table, or, for simplicity is the same age, the age of the single person. There is no true bequest motive.

Let the instantaneous utility function of singles be $u(c)$, and the instantaneous utility function of couples be $U(C)$. I assume that the two spouses are identical in their utility functions, and that each utility function is the same as that of singles. Let household utility be the sum of the utilities of each spouse, and then household consumption will then be divided evenly between the spouses. In particular let $U(C)=2 u\left(\frac{C}{k}\right)$ where $k$ is a returns-to-scale parameter: if there are no returns to scale, $k=2$, and household utility simply depends on per capita consumption. If there are complete returns-to-scale, $k=1$ and the household gets twice the utility from a given level of consumption that a single person would get. I assume that $1 \leq k \leq 2$.

The equation of motion of the marginal utility of the couple, $U_{t}$, is

$$
\frac{d U_{t}}{d t}=U_{t}\left(h_{t}+\rho-r\right)-\left(M_{t} \phi_{t}+F_{t} \mu_{t}\right)
$$

Let $g_{t}=\phi_{t}=\mu_{t}$, with the second equality coming from the assumption that the spouse are the same age. $\quad M_{t}$ and $F_{t}$ are the marginal utility of wealth of the widower and of the widow, and they will be equal because each surviving spouse would solve the same single's utility maximization problem, and would choose the same level of consumption. Because each spouse and the single person have the same life table and would have the same budget constraint should one spouse die, the single person and the surviving spouse would also solve the same utility maximization problem. The solution to that problem is characterized by

$$
\frac{d u_{t}}{d t}=u_{t}\left(g_{t}+\rho-r\right)
$$

and the marginal utility of wealth of the surviving spouse will equal the optimal marginal utility of consumption by the single person. That is, $u_{t}=M_{t}=F_{t}$.

\footnotetext{
${ }^{23}$ In the U.S. typically the annuity would decrease with the death of one of the spouses because the spouse benefit under Social Security would end. My second example will cover this case.
} 
Then

$$
\frac{d U_{t}}{d t}=U_{t}\left(2 g_{t}+\rho-r\right)-2 g_{t} u_{t}
$$

because $h_{t}=\phi_{t}+\mu_{t}=2 g_{t}$

In that $U(C)=2 u\left(\frac{C}{k}\right)$

$$
U_{t}=\frac{2}{k} u^{\prime}\left(\frac{C}{k}\right) \text { and } \frac{d U_{t}}{d t}=\frac{2}{k} u^{\prime}\left(\frac{C}{k}\right)\left(2 g_{t}+\rho-r\right)-2 g_{t} u^{\prime}(c)
$$

where $u^{\prime}(c)=u_{t}$.

Suppose for the moment that mortality risk and the parameters $\rho$ and $r$ are such that $g_{t}+\rho-r=0$ which would imply that

$$
\frac{d u_{t}}{d t}=u_{t}\left(g_{t}+\rho-r\right)=0
$$

In that bequeathable wealth and annuities of the couple and of the single are the same by assumption, the rate of wealth change will differ according to the level of consumption. Begin with the initial guess that the solution to the couple's and to the single's problem is that $C=c$. Then,

$$
\begin{aligned}
\frac{d U_{t}}{d t}= & \frac{2}{k} u^{\prime}\left(\frac{C}{k}\right)\left(2 g_{t}+\rho-r\right)-2 g_{t} u^{\prime}(C) \\
& =2 g_{t}\left(\frac{1}{k} u^{\prime}\left(\frac{C}{k}\right)-u^{\prime}(C)\right) .
\end{aligned}
$$

Thus initially, marginal utility of the couple will be increasing or decreasing according to the sign of

$$
\left(\frac{1}{k} u^{\prime}\left(\frac{C}{k}\right)-u^{\prime}(C)\right)
$$

This can be stated in terms of risk aversion.

$$
\begin{aligned}
& \text { Expanding } \frac{1}{k} u^{\prime}\left(\frac{C}{k}\right)-u^{\prime}(C) \text { at } k=1 \\
& \frac{1}{k} u^{\prime}\left(\frac{C}{k}\right)-u^{\prime}(C)=-\left[\frac{1}{k^{2}}\left\{u^{\prime}\left(\frac{C}{k}\right)+u^{\prime \prime}\left(\frac{C}{k}\right) \frac{C}{k}\right\}\right]_{k^{*}}(\mathrm{k}-1) \text { for some } 1 \leq k^{*} \leq k \leq 2 .
\end{aligned}
$$

The conventional measure of risk aversion evaluated at some level of consumption $c$ is 


$$
\gamma_{c}=\frac{-c u^{\prime \prime}(c)}{u^{\prime}(c)}
$$

so that

$$
u^{\prime}(c)+u^{\prime \prime}(c) c=u^{\prime}(c)-\gamma_{c} u^{\prime}(c)=u^{\prime}(c)\left(1-\gamma_{c}\right)=0 \text { for } \gamma_{c}=1
$$

and negative for $\gamma_{c}>1$.

The conclusion is that $\frac{d U_{t}}{d t}$ will be positive if risk aversion (which does not have to be constant) is greater than 1 . I will take this to be the normal case, and I have previously estimated (constant) $\gamma$ to be 1.12 .

Under the assumption that $u$ has risk aversion greater than one (globally), at least initially $\frac{d U_{t}}{d t}>0$ and $\frac{d u_{t}}{d t}=0$. Therefore the consumption path of the couple is declining and the consumption path of the single person is flat, so that consumption by the couples will become less than consumption by the single as shown in Figure 11.

Suppose that at some later time, the two consumptions become equal again. Now comparison of the consumption paths requires a modification of the preceding argument because $g_{t}+\rho-r>0$ due to increasing mortality risk with age, and to the fact that wealth of the couple is greater than wealth of the single person.

First, suppose as before that consumption by the surviving spouse would be the same as consumption by the single person. Then,

$$
\begin{aligned}
& \frac{d U_{t}}{d t}=\frac{2}{k} u^{\prime}\left(\frac{C}{k}\right)\left(2 g_{t}+\rho-r\right)-2 g_{t} u^{\prime}(C) \\
= & 2\left\{\left[\frac{1}{k} u^{\prime}\left(\frac{C}{k}\right)-u^{\prime}(C)\right] g_{t}+\frac{1}{k} u^{\prime}\left(\frac{C}{k}\right)\left[g_{t}+\rho-r\right]\right\} \\
> & 2 \frac{1}{k} u^{\prime}\left(\frac{C}{k}\right)\left[g_{t}+\rho-r\right]>2 u^{\prime}(C)\left[g_{t}+\rho-r\right] \\
= & 2 \frac{d u_{t}}{d t},
\end{aligned}
$$

using the fact that $\frac{1}{k} u^{\prime}\left(\frac{C}{k}\right)-u^{\prime}(C)>0$. Thus, were bequeathable wealth the same, $\frac{d U_{t}}{d t}>\frac{d u_{t}}{d t}$ provided risk aversion is greater than one. However, the wealth of the couple is now greater than the wealth of the single because consumption by the couple has been less. Therefore consumption by the surviving spouse would be greater than consumption by the single, which implies that the marginal utility of wealth of the surviving spouse is less than marginal utility evaluated at the consumption level of the 
single. Thus, $\frac{d U_{t}}{d t}>\frac{d u_{t}}{d t}$ when $u^{\prime}(\cdot)$ in $(\tau)$ is evaluated at the consumption level of the single. Evaluated at the consumption level of the surviving spouse $u_{t}$ would be smaller so that, a fortiori,

$$
\frac{d U_{t}}{d t}>\frac{d u_{t}}{d t}
$$

Thus, the path of consumption by the couple would remain below the path of consumption by the single as shown in the figure. This, however, cannot be the optimal path of consumption by the couple because at $T$ bequeathable wealth of the couple is positive: at $T$ bequeathable wealth of the single person is zero and the wealth of the couple is strictly greater; yet because desired consumption by the couple will be less that $A$ at $T$ the wealth of the couple wealth will increase. Therefore should each spouse live to the maximum age possible, the couple would die with positive wealth, which violates a transversality condition.

The conclusion is that initially consumption by the couple will be greater than consumption by the single person, and, therefore, that wealth of the couple will decline more rapidly than the wealth of the single person.

\subsection{Households have same resources per capita}

In the first example, the couple had the same resources as the single. Now I suppose that each spouse has the same resources as the single, so that per capita resources are the same. In particular, let the wealth of each spouse be $w$ and the real annuity of each be $A$. Thus, initially the couple has wealth of $2 w$ and a real annuity of $2 A$. Should one spouse die immediately the survivor will have wealth of $2 w$ and an annuity of $A$. I will compare the rate of wealth decumulation of the couple with a single with wealth $w$ and annuity $A$. The difference between the couple and the single will be in returns-to-scale in consumption, the risk of dying with wealth, and the level of wealth of a survivor. It will be useful to consider the problem in terms of per capita wealth, annuities and consumption. In that initially per capita wealth and annuities are the same for the couple as for the single, the rate of wealth decumulation will only depend on which has greater per capita consumption.

As before let the utility function of the couple be $U(C)=2 u\left(\frac{C}{2 k}\right) \equiv 2 u\left(\frac{c}{k}\right)$ where $c=\frac{C}{2}$ is per capita consumption and, in a change of notation, $k$ is a rescaled personequivalents parameter with $k=\frac{1}{2}$ indicating that each married person is equivalent to $\frac{1}{2}$ of a single person, (complete returns-to-scale) and $k=1$ indicating two marrieds are 
equivalent to two singles (no returns-to-scale). I will take the case of constant relative risk aversion because, as we will see, the results depend on parameters even in the context of this utility function, so little is to be gained from greater generality. Thus, let

$$
u(c)=\frac{c^{1-\gamma}}{1-\gamma}
$$

and to simplify notation I will let $r=\rho$.

Then as before

$$
\frac{d U_{t}}{d t}=U_{t}\left(h_{t}+\rho-r\right)-\left(M_{t} \dot{\phi}_{t}+F_{t} \mu_{t}\right)
$$

and

$$
\frac{d U_{t}}{d t}=U_{t t} \frac{d C_{t}}{d t}
$$

so that

$$
\begin{aligned}
& \frac{d C_{t}}{d t}=2 \frac{U_{t}}{U_{t t}} g_{t}-2 \frac{M_{t}}{U_{t t}} g_{t} \\
& =-2 \frac{C_{t}}{\gamma} g_{t}+4 g_{t} \frac{c_{w}^{-\gamma}}{\gamma k^{\gamma-1}\left(\frac{C}{2}\right)^{-\gamma-1}}
\end{aligned}
$$

where $c_{w}$ is the consumption that a surviving spouse would choose $\left(M_{t}=c_{w}^{-v}\right)$ and using the facts that

$$
U_{t}=k^{\gamma-1}\left(\frac{C}{2}\right)^{-\gamma} \text { and } U_{t t}=-\frac{\gamma}{2} k^{\gamma-1}\left(\frac{C}{2}\right)^{-\gamma-1}
$$

Then, because $\frac{d c_{t}}{d t}=2 \frac{d\left(\frac{C}{2}\right)}{d t}$

$$
\frac{d c_{t}}{d t}=-\frac{2}{\gamma} c_{t} g_{t}+\frac{2}{\gamma} \frac{c_{w}^{-\gamma} c_{t}}{k^{\gamma-1} c_{t}^{-\gamma}}
$$

Thus for the couple

$$
\frac{d \ln c_{t}}{d t}=-\frac{2}{\gamma} g_{t}\left[1-k^{1-\gamma}\left(\frac{c_{t}}{c_{w}}\right)^{\gamma}\right]
$$

For the single 


$$
\frac{d \ln c_{t}}{d t}=-\frac{1}{\gamma} g_{t}
$$

In that per capita wealth and annuities of the couple and the single are the same, a good initial guess is that the couple chooses the same level of consumption per capita as the single so that the two households would decumulate wealth at the same rate. Their consumption paths will be the same if the rates of change of log consumption are the same or if

$$
-\frac{2}{\gamma} g_{t}\left[1-k^{1-\gamma}\left(\frac{c_{t}}{c_{w}}\right)^{\gamma}\right]=-\frac{1}{\gamma} g_{t}
$$

or

$$
k^{1-\gamma}\left(\frac{c_{w}}{c_{t}}\right)^{-\gamma}=\frac{1}{2}
$$

Table 1 gives combinations of $k, \gamma$ and $\frac{c_{w}}{c_{t}}$ that satisfy this equality. Larger values of each parameter than those shown in the table will make the left-hand side of ( 8 ) less than $\frac{1}{2}$, and then couples will reduce their consumption faster than singles. ${ }^{24}$ Consider, for example, $k=0.63$, which is the implicit per person equivalent in the poverty scale for the elderly. ${ }^{25}$ If $\frac{c_{w}}{c_{t}}=1.8$ and $\gamma=1.83$,

$$
\left.\frac{d \ln c_{t}}{d t}\right|_{\text {couples }}=\left.\frac{d \ln c_{t}}{d t}\right|_{\text {singles }} .
$$

If $\gamma>1.83$ and the other parameters remain the same the LHS of (9) will become less than the RHS: that is increases in risk aversion would reduce (algebraically) the slope of the consumption path of couples relative to the slope for singles.

Suppose the left-hand side of $(8)$ is less than $\frac{1}{2}$ so that

$$
\left.\frac{d \ln c_{t}}{d t}\right|_{\text {couples }}<\left.\frac{d \ln c_{t}}{d t}\right|_{\text {singles }}
$$

as shown in Figure 12. Than per capita consumption by each of the spouses would become less than consumption by the single so that per capita wealth of the couple would become greater than per capita wealth of the single. If, as time passes, the LHS of (8) remains less than one-half, (10) will continue to hold and the consumption path of couples will remain below the consumption path of singles. However, at $T$ the wealth of

\footnotetext{
${ }^{24}$ Note that $\frac{c_{w}}{c_{t}}>1$ and $\frac{1}{2} \leq k \leq 1$.

${ }^{25}$ According to the poverty scale an elderly couple needs $26 \%$ more than an elderly single.
} 
the single is zero, which means than the wealth of the couple is positive, and the couple will hold positive wealth should it survive to the greatest age possible. This violates a transversality condition.

To see whether this happens, suppose that at, say, $\tau$ per capita consumption by the couple is the same as by the single. If the LHS of ( $S$ ) continues to be less than $\frac{1}{2}$, then

$$
\left.\frac{d \ln c_{t}}{d t}\right|_{\text {couples }}<\left.\frac{d \ln c_{t}}{d t}\right|_{\text {singles }}
$$

will hold at $\tau$. The only change in the LHS of (8) from the initial situation is in $\frac{c_{w}}{c_{t}}: c_{w}$ is consumption by the survivor should one spouse die, and $c_{t}$ is consumption by the couple. Therefore, to see if the LHS of (8) is less than $\frac{1}{2}$ we need to examine $\frac{c_{w}}{c_{t}}$ at $\tau$.

In the singles model

$$
\frac{d \ln c_{t}}{d t}=-\frac{g_{t}}{\gamma} \text { or } c_{t}=c_{0} e^{-\frac{1}{\gamma} \int_{0}^{t} g_{t} d t}
$$

The survivor function $a_{t}$ is related to $g_{t}$ by $\frac{d \ln a_{t}}{d t}=-g_{t}$ which implies that

$$
a_{t}=e^{-\int_{0}^{t} g_{t} d t}
$$

Thus,

$$
c_{t}=c_{0} a^{\frac{1}{\tilde{t}}}
$$

and $c_{0}$ is a function of initial wealth and annuities. This implies that for two different consumption paths $\left\{\widehat{c}_{t}\right\}$ and $\left\{\widetilde{c}_{t}\right\}$ based on different wealth or annuity levels

$$
\frac{\widehat{c}_{t}}{\widetilde{c}_{t}}=\frac{\widehat{c}_{0}}{\widetilde{c}_{0}}
$$

as long as neither path is liquidity constrained. At time $0, I$ assumed that the ratio of per capita consumption by a survivor (whom I shall call an "original widow") to per capita consumption by the couple was large enough that the LHS of $(8)$ was less than $\frac{1}{2}$. If at $\tau$ the wealth of the couple is large enough that a new widow could attain the consumption level of the original widow, the ratio of consumption by the new widow to per capita consumption by the couple would be as large or larger because of (11) and 
the LHS of ( 8 ) would continue to be less than $\frac{1}{2}$. Therefore, the slope of the consumption path of the couple would again be less than the slope of the consumption path of the single and couple's path would remain below the single's path as shown in the figure. One might imagine this is the usual situation, particularly because per capita consumption by the couple has been less than consumption by the single so that the ratio of wealth of the couple to the wealth of the single is now greater than two. ${ }^{26}$ Then, the couple's consumption path cannot be globally optimal because of the transversality condition. The global solution would require that initially the couple consume at a greater rate than the single, and, therefore, the couple would dissave at a greater rate.

By a similar argument if initially the path of consumption by couples is flatter than the path of consumption by singles (the LHS of $(8)$ is greater than $\frac{1}{2}$ ), initial consumption will be lower and the rate of wealth decumulation by couples will be smaller.

According to this argument, large values of $k, \gamma$ and $\frac{c_{w}}{c_{t}}$ will lead to a greater rate of dissaving by couples relative to singles. Larger returns-to-scale in consumption (smaller $k$ ) increase the utility from consumption by the couple, but decrease marginal utility. Therefore, with small $k$ the couple will reduce present consumption, reducing dissaving. Greater risk aversion, $\gamma$, reduces consumption by both singles and couples, but more for singles: couples can share the increasing importance of the risk of dying early. Thus as risk aversion increases the rate of dissaving by both declines but it declines more among singles. ${ }^{27}$ A large ratio of $c_{w}$ to $c_{t}$ happens when the risk of living to extreme old age is small (the survivor curve has a thin tail), as shown in Figure 13. Should widowing happen at $t=0$, the survivor would consume at a high rate because the initial wealth of the survivor would be $2 w$, and there is little necessity to guard against extreme old-age. The single would also consume at a higher rate, but the response would be less because wealth is just $w$.

I have said that at $\tau$ in Figure 12, we would expect that the LHS of (8) would be less than $\frac{1}{2}$, which would lead to the conclusions about relative rates of dissaving that I have been discussing. However, this line of reasoning does not hold if the wealth of the couple at $\tau$ is too small, because then $c_{w}$, consumption by a new widow, would have to be small. The wealth of the couple at $\tau$ could be small relative to the wealth of an original widow as follows: The level of consumption by the original widow at time 0 is determined partly by the shape of the survivor function at times beyond $T$. As shown

\footnotetext{
${ }^{26}$ I will return to this issue below.

${ }^{27}$ This is similar to what Kotlikoff and Spivak (1981) found in a two-period model.
} 
in Figure 14, the survivor function could cause the original widow to set consumption only marginally greater than per capita consumption by the couple, and, as a consequence, have substantially greater wealth than the couple at $\tau$. In Figure $12, c_{w}$ would be only slightly above $c_{s}$ until time $T$. Then a new widow at $\tau$ could not attain the consumption level of the original widow, and, as a consequence, the LHS of ( 8 ) might not be less than $\frac{1}{2}$. Should that happen, the consumption paths of the couple and the single would cross, and there is no longer a logical barrier preventing the consumption path of the couple from being optimal. Finally, by continuity, a path of consumption by the couple that has initial consumption slightly below initial consumption by the single could be optimal.

Nonetheless, an implication is that large values of $k, \gamma$ and $\frac{c_{w}}{c_{t}}$ (all of which would steepen the consumption path of the couple relative to the single) will, if initial per capita consumption by the couple and by the single are the same, increase the wealth of the couple relative to the single, so that at $\tau$ it is more likely that $\frac{c_{w}}{c_{t}}$ is large, and that the LHS of ( 8 ) will be less than $\frac{1}{2}$. Should that happen the optimal consumption path would require that initially per capita consumption by the couple be higher than consumption by the single leading to higher rates of dissaving by couples. Of course, this result cannot be established with certainty without a global specification of the survivor curve.

4.3. Summary of the effects of marital status on dissaving.

Whether couples dissave more or less rapidly than singles depends firstly on the economic resources of each. In the first example, a surviving spouse had twice the per capita annuity of the couple, causing the couple to consume relatively more out of bequeathable wealth, provided risk aversion was greater than one. Risk aversion matters because it reduces consumption by both couples and singles, but the reduction is greater for singles.

In the second example, per capita resources of the couple and of the single were made the same. Then the comparison of rates of dissaving depended on parameters of the utility function and on the risk of a very long life. If that risk is large couples will tend to dissave more rapidly than singles.

\section{Empirical findings.}

The empirical implications of the single's model are: $\frac{d l n c_{t}}{d t}<0$ at some age $\tau$ 
relatively early after retirement. If a second person has the same wealth and annuity stream but is older, $\frac{d l n c_{t}}{d t}$ will be (algebraically) less. $\frac{d w_{t}}{d t}<0$ for $t>\tau$, and $\frac{d w_{t}}{d t}$ will be smaller for the older but otherwise identical person. A bequest motive will decrease $c_{t}$, increase $\frac{d c_{t}}{d t}$ and increase (algebraically) $\frac{d w_{t}}{d t}$.

In the couple's model $\frac{d C_{t}}{d t}<0$ if one spouse is very old and the other is moderately old (age $\tau$ as in the single's problem). If a second couple has the same wealth and annuities but is older $\frac{d C_{t}}{d t}$ will be (algebraically) less. Wealth will decline in these circumstances. If the couple has a bequest motive, the effects are the same as in the single's model. Couples could dissave either more or less rapidly than singles, depending on the economic resources, the paths of mortality risk and utility function parameters.

To compare the predictions of the analyses with outcomes, I have taken some empirical findings about consumption levels, changes in consumption and wealth changes from other papers. ${ }^{28}$ The consumption measures are, however, rather deficient because they measure just part of consumption. Nonetheless, the consumption and wealth data all lead to similar conclusions.

Table 2 shows the change in a partial measure of consumption from the Retirement History Survey (RHS). The RHS has direct measures of the following categories of consumption: food purchased in grocery stores, food from vendors and home delivery, food purchased away from home, nonfood items purchased in grocery stores, gifts and donations, recreation and membership fees, and gasoline and other transportation expenses (but excluding automobile purchases). I estimate that the covered categories comprise about $34 \%$ of total consumption by the elderly (Hurd, 1992b).

The changes are averages over a 10-year period. The unit of observation is a two-year change in a household where the respondents are retired. The bulk of the observations would be over people in their late 60's and early 70's.

As measured in the table, consumption declines, and at a rather high rate. Consumption by couples declines more rapidly than by singles, but there is no control for total resources. Thus the $\mathrm{LCH}$ model makes no prediction about the relative rates.

Table 3 shows wealth change from four panel data sets. Again the change is calculated over retired households. We consistently see dissaving, and the rates from the RHS and the SIPP are rather close.

\footnotetext{
${ }^{28}$ It is rather important to control for retirement status: predictions about consumption and saving behavior while employed are much more difficult because of the income changes associated with retirement and because of changes in the utility function associated with the increased leisure in retirement. All the results I give are calculated over retirees.
} 
Table 4 has annual rates of dissaving by age and marital status from the SIPP. ${ }^{29}$ The rate of dissaving increases with age, except for couples 75 or over. Couples dissave less rapidly than singles.

Table 5 shows the results from a test of the bequest motive. It is based on the idea that the marginal utility from bequests will be greater among those with children than among those without. If that is the case, the bequest motive predicts that consumption by those with children will decline more slowly than by those without children. ${ }^{30}$ Among singles consumption does decline more slowly if the single person has children, but the difference is not statistically significant. Among couples with children consumption declines more rapidly. The overall result shows no support for a bequest motive.

Table 6 has a similar test based on rates of wealth change: a bequest motive says that wealth should decline more slowly among parents. This is found in just one comparison of the four. Again these results give no support for a bequest motive. ${ }^{31}$

\section{Conclusion.}

Couples choose a consumption level knowing that should one die the survivor will finance consumption from the wealth of the couple and from an annuity stream, which would generally be different from the annuity stream of the couple. The survivor's optimal consumption path will depend on the survivor's preferences (including a true bequest motive), mortality risk and economic resources. This choice puts a value on the wealth of the couple, the marginal utility of wealth. If the marginal utility is high (as it would be if the survivor were young, or had a bequest motive, or had a low annuity), the couple would choose a low level of consumption, thus holding more wealth. In this aspect, the situation looks like a bequest motive outside the family: the couple holds more wealth in anticipation of giving a larger "bequest."

However, the decision making is more interesting empirically than in the case of a single person contemplating a bequest to the next generation. One can observe in a typical household-level data set the complete financial resources that are involved in the

${ }^{29}$ Age is the age of the husband.

${ }^{30} \mathrm{~A}$ comparison of levels of consumption is not valid because of differences in wealth and annuities.

${ }^{31}$ This test has been criticized on the grounds that parents may be able to dissave more rapidly than nonparents because their children will act as insurance against an excessively long life. Then the two effects (bequest motive and insurance) may roughly cancel, making the rates of dissaving by parents and nonparents approximately. My reservation about this criticism is that we observe very few transfers from children to parents in data. 
decision, including the likely resources of the survivor. This is rarely, if ever, true for the study of a true bequest because data are rarely linked across generations when each generation lives in a separate household. Further, the conscious choice of a consumption level with an eye to the resources of the survivor is more plausibly maintained because the survivor is involved in the decision making of the couples.

The empirical evidence based on four data panel sets is consistent with a main prediction of the LCH: wealth declines in old age after retirement. Under the assumption that those with children have a bequest motive and those without children do not (or have a smaller bequest motive), the data show no support for an empirically important bequest motive. 


\section{References}

Attanasio, Orazio and Martin Browning, "Consumption over the Life-Cycle and over the Business Cycle," American Economic Review, 85 (5) 1119-1137

Bernheim, Douglas B, 1987,. "Dissaving after Retirement: Testing the Pure life Cycle Hypothesis," in Issues in pension economics. Eds.: Zvi Bodie, John B. Shoven and David A. Wise. Chicago: University of Chicago Press, pp. 237-274.

Blundell, Richard, Martin Browning and Costas Meghir, 1994, "Consumer Demand and the Life-Cycle Allocation of Household Expenditures," Review of Economic Studies, 61 (1) $57-80$

Brown, Jeff and James Poterba, 1998, "Joint Life Annuities and Annuity Demand by Married Couples," presented at the NBER Summer Insitute

Browning, Martin and Annamaria Lusardi, 1996, "Household Saving: Micro Theories and Micro Facts," Journal of Economic Literature, XXXIV (4) 1797-1855

Diamond, Peter A. and Jerry Hausman, 1984, "Individual Retirement and Savings Behavior." Journal of Public Economics, 23, pp 81-114.

Friedman, Benjamin M. and Mark Warshawsky, 1988, "Annuity Prices and Saving Behavior in the United States," in Pensions in the U.S. Economy, Eds.: Zvi Bodie, John B. Shoven and David A. Wise. Chicago: University of Chicago Press, pp 53-77.

Grad, Susan, 1996, "Income of the Population 55 or Older, 1994," SSA publication 1311871, Office of Research and Statistics, Social Security Administration, Washington, D.C.

Hubbard, R. Glenn, Jonathan Skinner, and Stephen P. Zeldes, 1995, "Precautionary Saving and Social Insurance," Journal of Political Economy, 103 (2) 360-399 Hurd, Michael D., 1987, "Savings of the Elderly and Desired Bequests," The American Economic Review, 77 (3), pp. 298-312.

Hurd, Michael D., 1989, "Mortality Risk and Bequests," Econometrica, 57 (4), 779-813. Hurd, Michael D., 1991, "The Income and Savings of the Elderly," final report to AARP Andrus Foundation, typescript, SUNY, Stony Brook.

Hurd, Michael D., 1992a, "Forecasting the Consumption, Income and Wealth of the Elderly," Final Report to the Social Security Administration, typescript, SUNY, Stony Brook.

Hurd, Michael D., 1992b, "Wealth Depletion and Life-Cycle Consumption by the Elderly," in Topics in the Economics of Aging, Ed.: David A. Wise. Chicago: The University of Chicago Press, 135-160. 
Hurd, Michael D., 1993, "The Effect of Changes in Social Security on Bequests," Journal of Economics, Supplement 7, Bernhard Felderer, ed., 1993, pp. 157-176.

Hurd, Michael D., 1995, "Mortality Risk and Consumption by Couples," presented at the IFS-Bank of Portugal Conference on The Microeconomics of Saving and Consumption Growth, Lisbon, November

Kotlokoff, Laurence J., 1988, "Intergenerational Transfers and Savings," The Journal of Economic Perspectives, 2 (2), pp 41-59.

Kotlokoff, Laurence J., and Avia Spivak, 1981, "The Family as an Incomplete Annuity Market," The Journal of Political Economy, 89 (2) pp. 372-391.

Kotlikoff, Laurence J. and Lawrence Summers, 1988, "The Contribution of Intergenerational Transfers to Total Wealth: A Reply," in Modelling the Accumulation and Distribution of Wealth, Eds: Denis Kessler and Andre Masson, New York: Oxford University Press, 53-67.

Laitner, John and F. Thomas Juster, 1996, "New Evidence on Altruism: A Study of TIAA-CREF Retirees," American Economic Review, 86 (4) 893-908.

Levin, Laurence, 1995, "Demand for Health Insurance and Precautionary Motives for Savings among the Elderly," Journal of Public Economics, 57 (3) 337-367.

Mirer, Thad, 1980, "The Dissaving Behavior of the Retired Aged," Southern Economic Journal, 46 (4) pp 1197-1205.

Modigliani, Franco, 1986, "Life Cycle, Individual Thrift, and the Wealth of Nations." American Economic Review, 76, (3) pp 297-313.

Modigliani, Franco, 1988, "The Role of Intergenerational Transfers and Life Cycle Saving in the Accumulation of Wealth," The Journal of Economic Perspectives, 2 (2), pp 1540.

Soldo, Beth, Michael D. Hurd, Willard Rodgers and Robert Wallace, 1997, "Asset and Health Dynamics among the Oldest-Old: An Overview of the Survey," Journal of Gerontology, 52B (May), pp 1-20.

Yaari, Menahem E., 1965, "Uncertain Lifetime, Life Insurance and the Theory of the Consumer," Review of Economic Studies, 32, pp 137-150. 
Table 1

Values of risk aversion parameter leading to equal rates of consumption decline by couples and by singles

\begin{tabular}{llll}
\hline \hline $\begin{array}{l}\text { Ratio of consumption } \\
\text { by survivor to per capita }\end{array}$ & \multicolumn{3}{c}{ Person equivalents $(k)$} \\
\cline { 2 - 4 } consumption by couple & 0.63 & 0.70 & 0.75 \\
\hline 1.6 & 25.8 & 2.97 & 2.22 \\
1.8 & 1.83 & 1.46 & 1.35 \\
1.9 & 1.28 & 1.18 & 1.14 \\
1.95 & 1.12 & 1.08 & 1.07 \\
\hline
\end{tabular}

Note: larger values of parameters will reduce slope of consumption pach of couples relative to singles.

Table 2

Annual rate of consumption change (percent), average over 19691979

\begin{tabular}{ccc}
\hline \hline Singles & Couples & All \\
\hline-3.8 & -4.2 & -4.1 \\
\hline
\end{tabular}

Source: Hurd, 1992b, calculated from 1969-1979 RHS.

Note: Consumption measure includes about 34 percent of total consumption.

Calculated over retired singles and couples approximately of age 60-74. 
Table 3

Average Bequeathable Wealth Change in Panel Data

\begin{tabular}{lcl}
\hline & $\begin{array}{c}\text { Annual Rate of } \\
\text { Wealth Change }\end{array}$ & Source \\
\hline Data Set & $-1.2 \%{ }^{* *}$ & Mirer, 1980 \\
\hline 1963, 1964 Federal Reserve* & $-5.0 \%$ & Diamond and Hausman, 1984 \\
NLS Mature Men & $-4.5 \%$ & Hurd, 1987 \\
RHS 1969-1979 (Singles) & $-1.6 \%$ & Hurd, 1987 \\
RHS 1969-1979 (Couples) & $-3.9 \%$ & Hurd, 1991 \\
SIPP 1984, 1985 (Singles) & $-1.8 \%$ & Hurd, 1991 \\
SIPP 1984, 1985 (Couples) & \multicolumn{2}{l}{} \\
\hline Survey of Financial Characteristics of Consumers and Survey of Changes in Family Financing. \\
\hline Median wealth change
\end{tabular}

Table 4

Annual Percentage Change in Average Wealth

\begin{tabular}{lccc}
\hline \hline Age Range & Singles & Couples & A.l \\
\hline $65-69$ & -0.1 & 2.3 & 1.3 \\
$70-74$ & -4.8 & -5.9 & -5.3 \\
$75+$ & -6.0 & -3.7 & -5.1 \\
All & -3.9 & -1.8 & -2.9 \\
\hline
\end{tabular}

Source: Hurd. 1991. Calculated from 1984 SIPP, waves 4 and 7 . Includes housing and nonhousing wealth 
Table 5

Consumption and Consumption Change

\begin{tabular}{|c|c|c|c|c|}
\hline & \multicolumn{2}{|c|}{ Singles } & \multicolumn{2}{|c|}{ Couples } \\
\hline & No Children & Children & No Children & Children \\
\hline $\mathrm{C}_{0}$ & 22.7 & 21.4 & 37.9 & 38.6 \\
\hline $\mathrm{C}_{2}$ & 21.4 & 20.8 & 36.0 & 36.2 \\
\hline $\begin{array}{l}C_{2}-C_{0} \\
\text { (Std. err.) }\end{array}$ & $\begin{array}{c}-1.3 \\
(0.34)\end{array}$ & $\begin{array}{c}-0.6 \\
(0.23)\end{array}$ & $\begin{array}{c}-1.9 \\
(0.54)\end{array}$ & $\begin{array}{c}-2.4 \\
(0.30)\end{array}$ \\
\hline Bequest motive & \multicolumn{2}{|c|}{ yes } & \multicolumn{2}{|c|}{ no } \\
\hline Observations & 1160 & 2484 & 563 & 2451 \\
\hline
\end{tabular}

Source: Hurd, 1992b

Notes: 1969-1979 RHS. Consumption in dollars per week (1969 prices). Consumption in seven categories. about $34 \%$ of total consumption.

Table 6

Average Annual Real Wealth Change (percent)

\begin{tabular}{lllll}
\hline & \multicolumn{2}{c}{ Singles } & \multicolumn{2}{c}{ Couples } \\
\cline { 2 - 5 } & RHS & SIPP & RHS & SIPP \\
\cline { 2 - 5 } Children & -4.8 & -2.6 & -1.7 & -4.5 \\
No Children & -3.9 & -3.2 & -0.2 & -0.2 \\
Bequest motive & no & yes & no & no \\
\hline Sources: RHS: Hurd, 1987; SIPP: Wang, 1991. & & \\
Note: Retired singles and couples. RHS: bequeathable wealth excluding housing. & 1984 \\
SIPP waves 4 and 7: bequeachable wealth including bousing. & \\
\hline
\end{tabular}



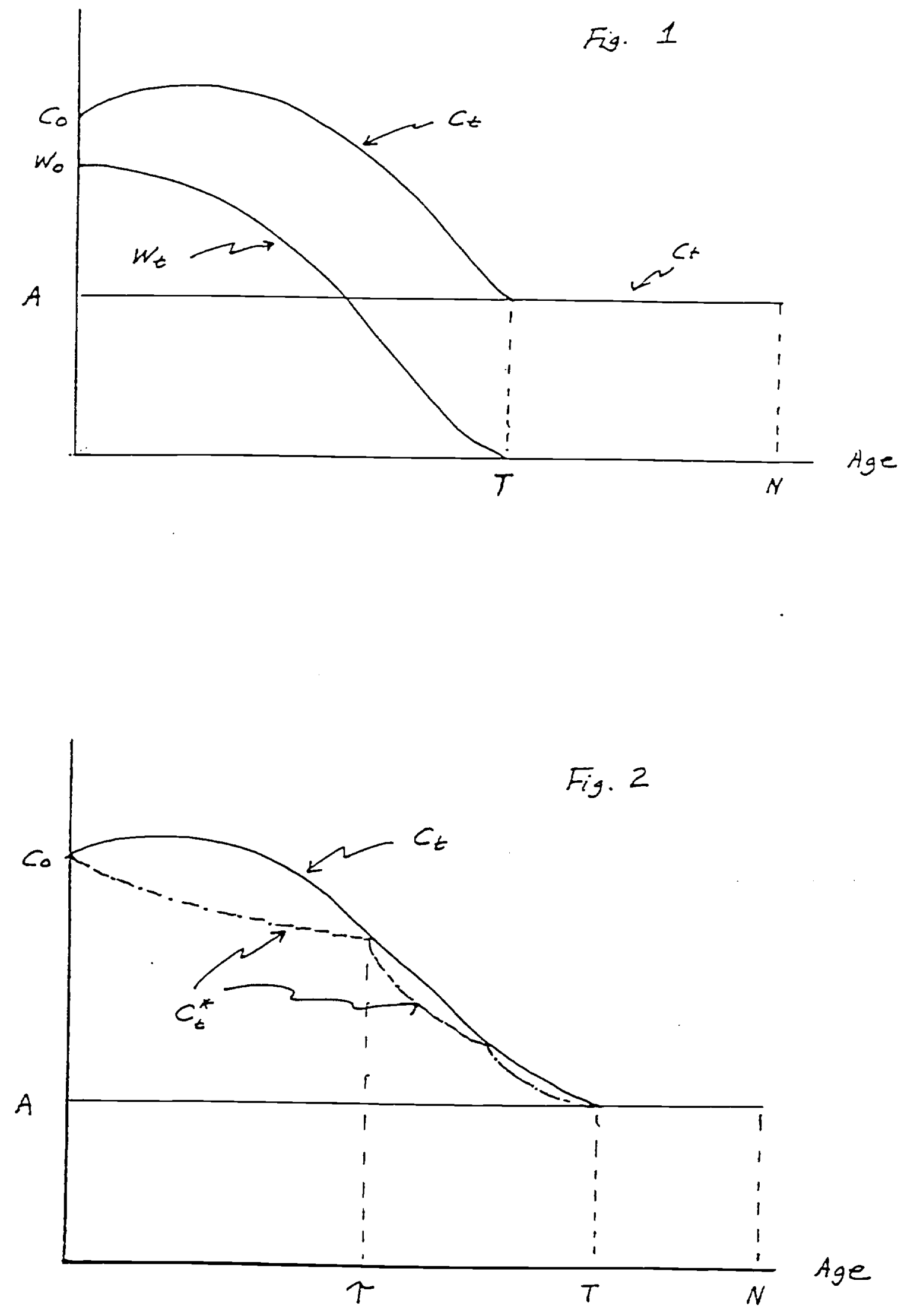
Fig. $3 a$

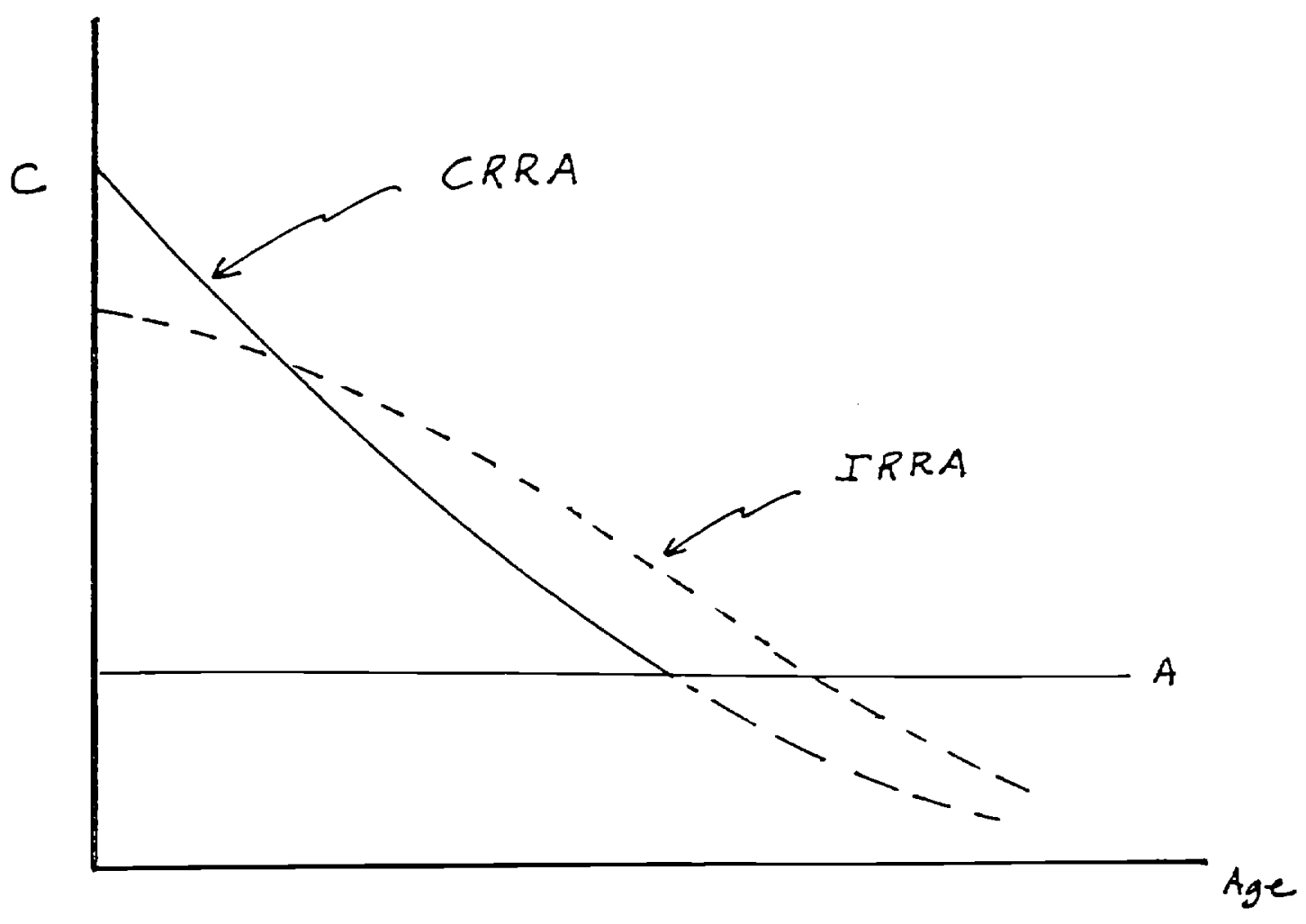

$F i \dot{g} . \quad 3 b$

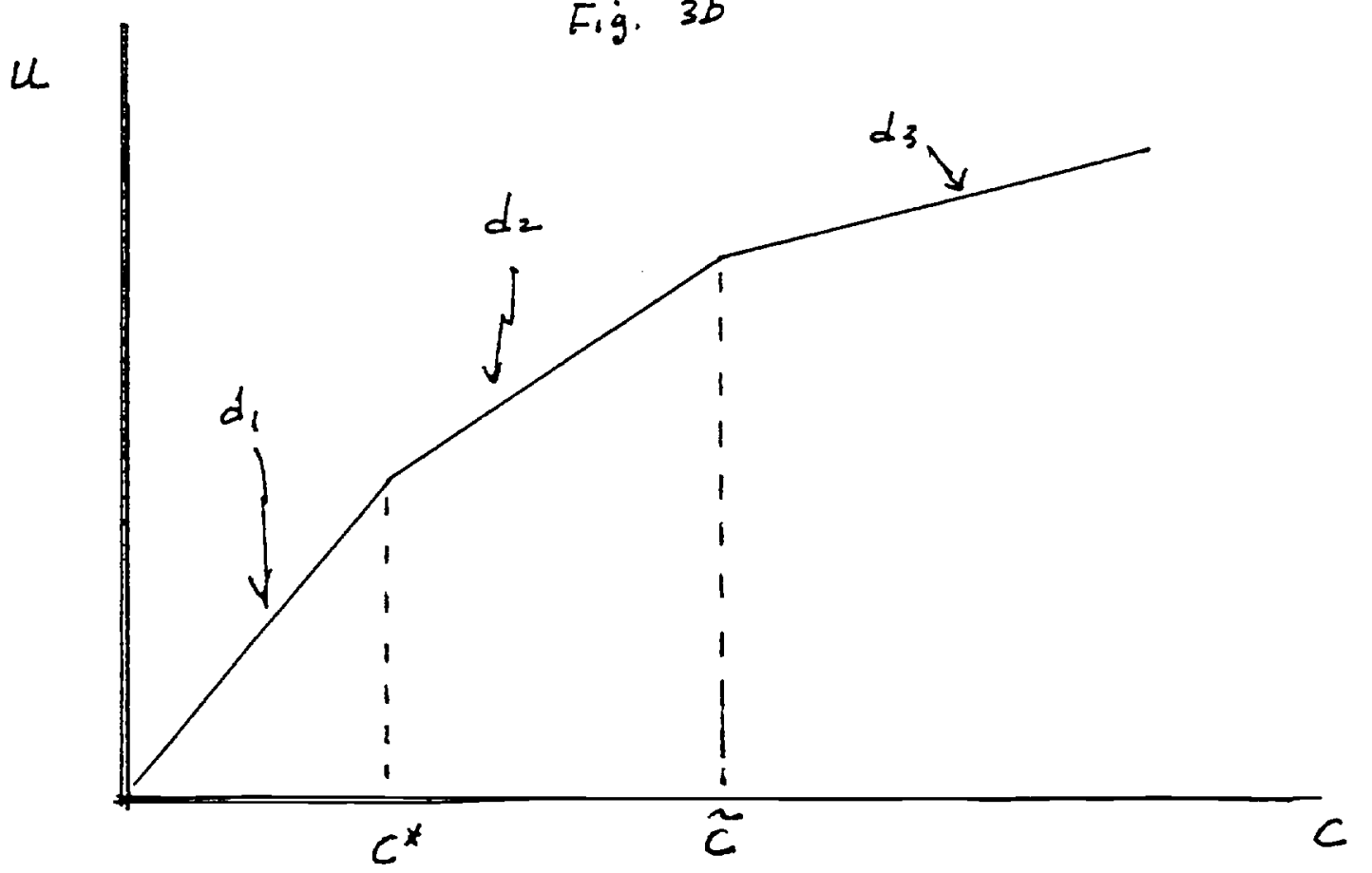


Fig $3 c$
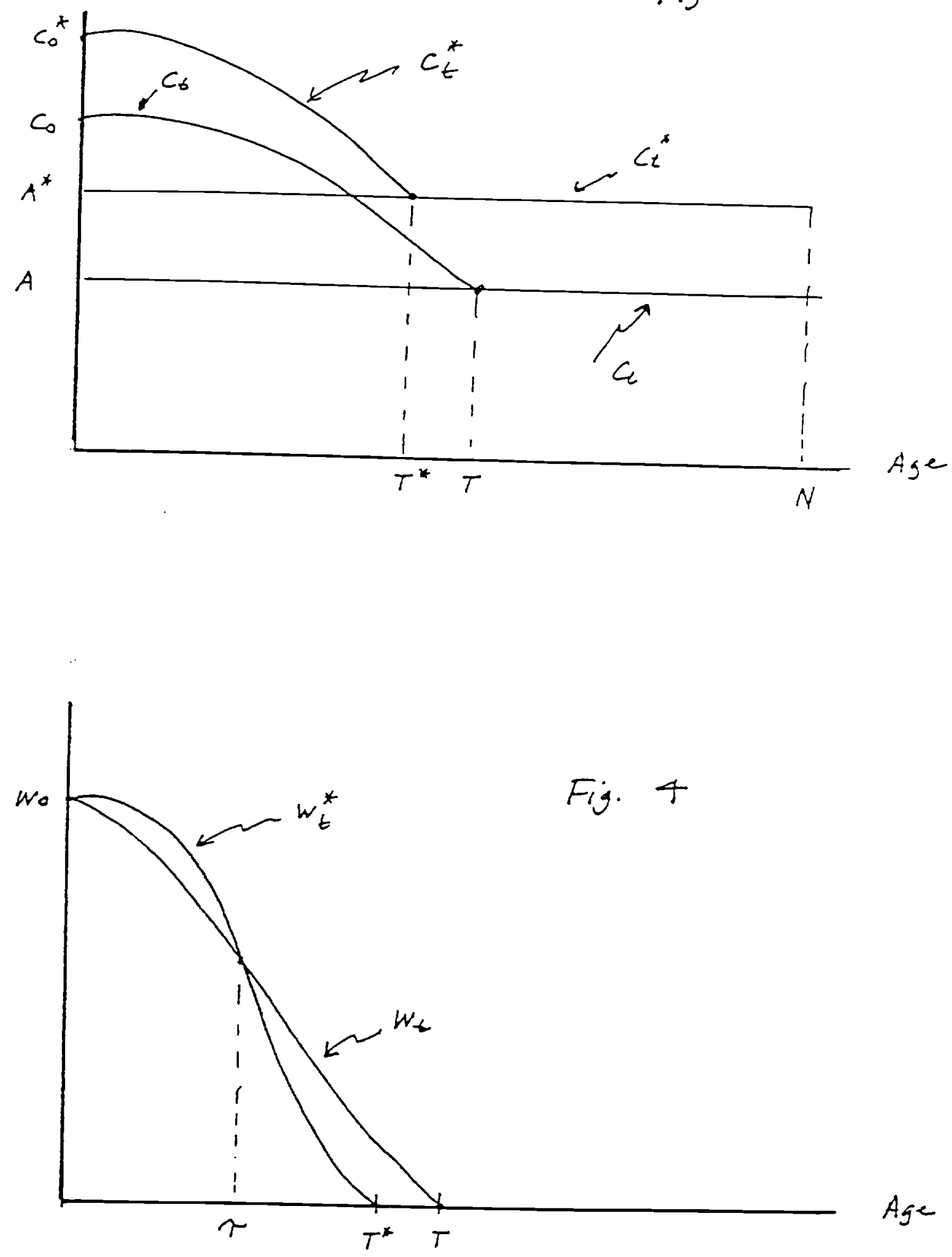
Fig. 5
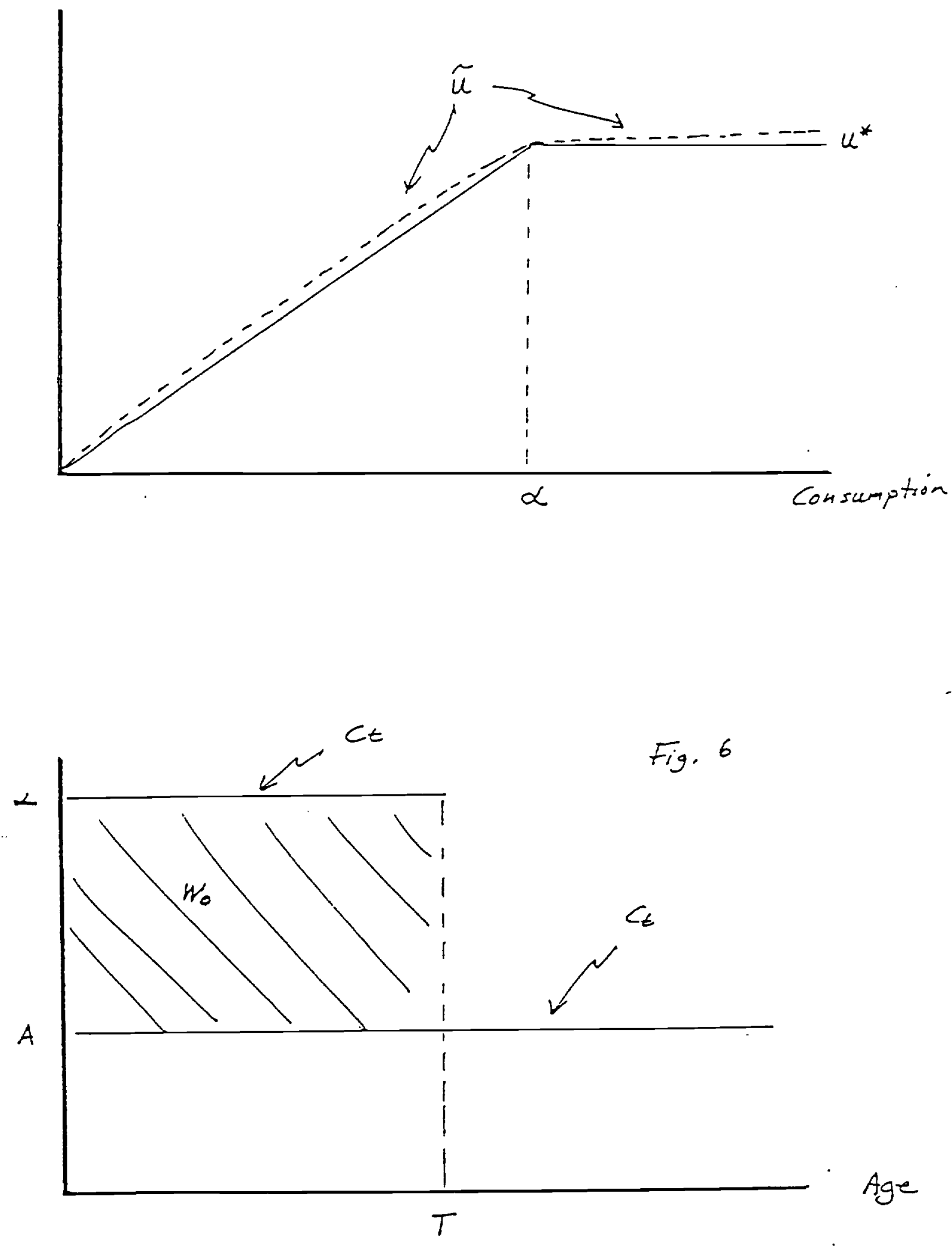

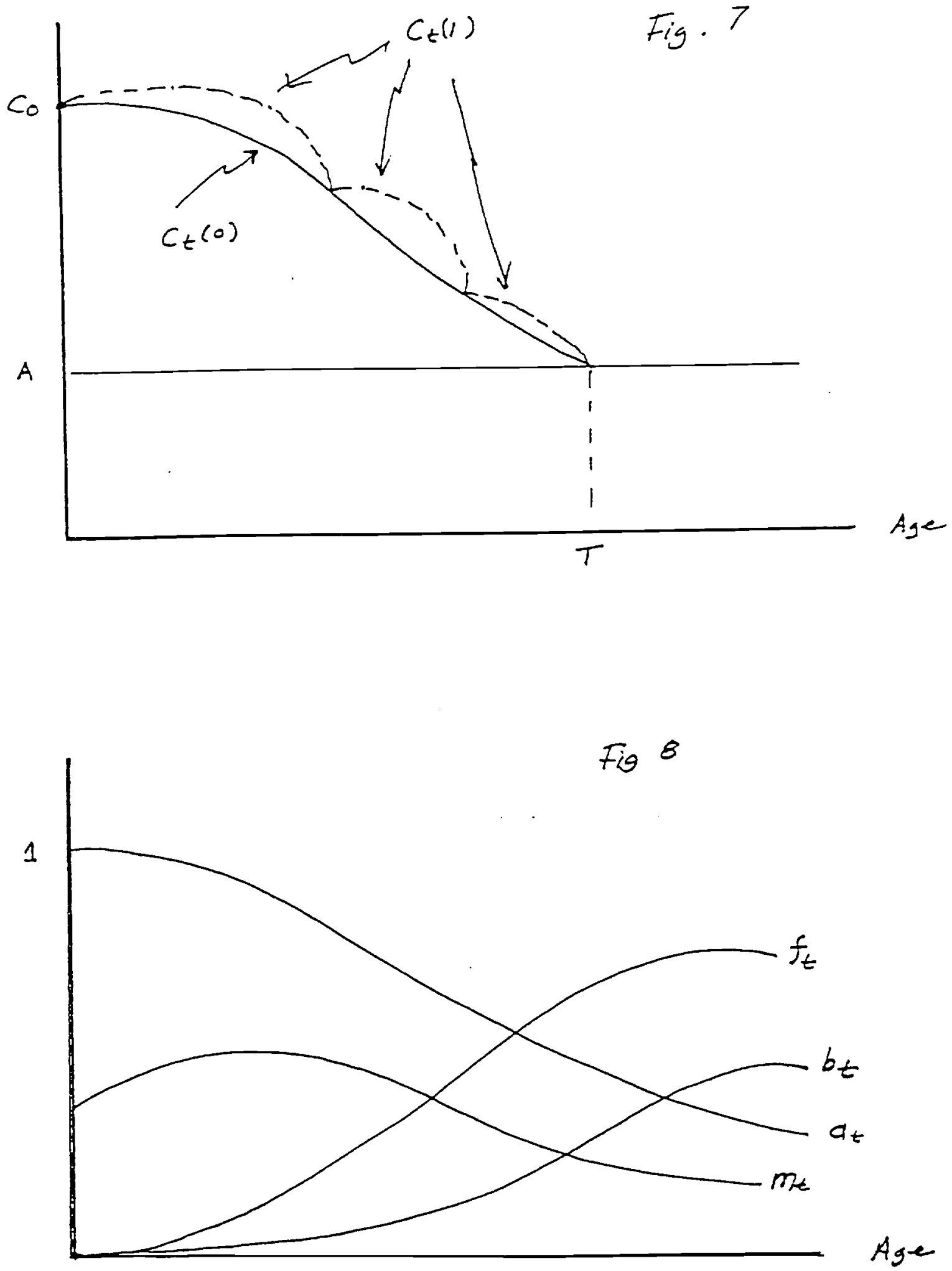

Age 

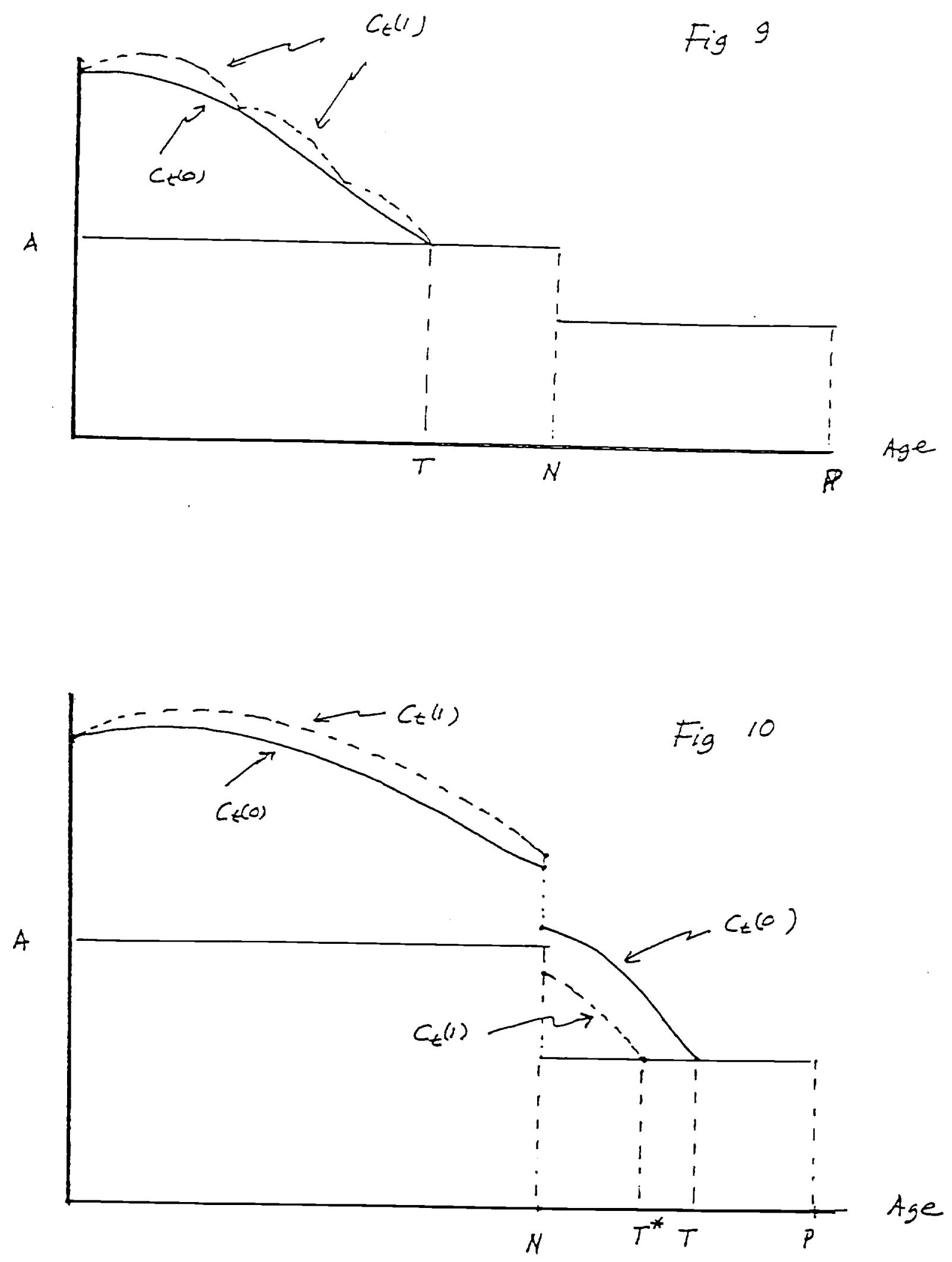
Fig 11

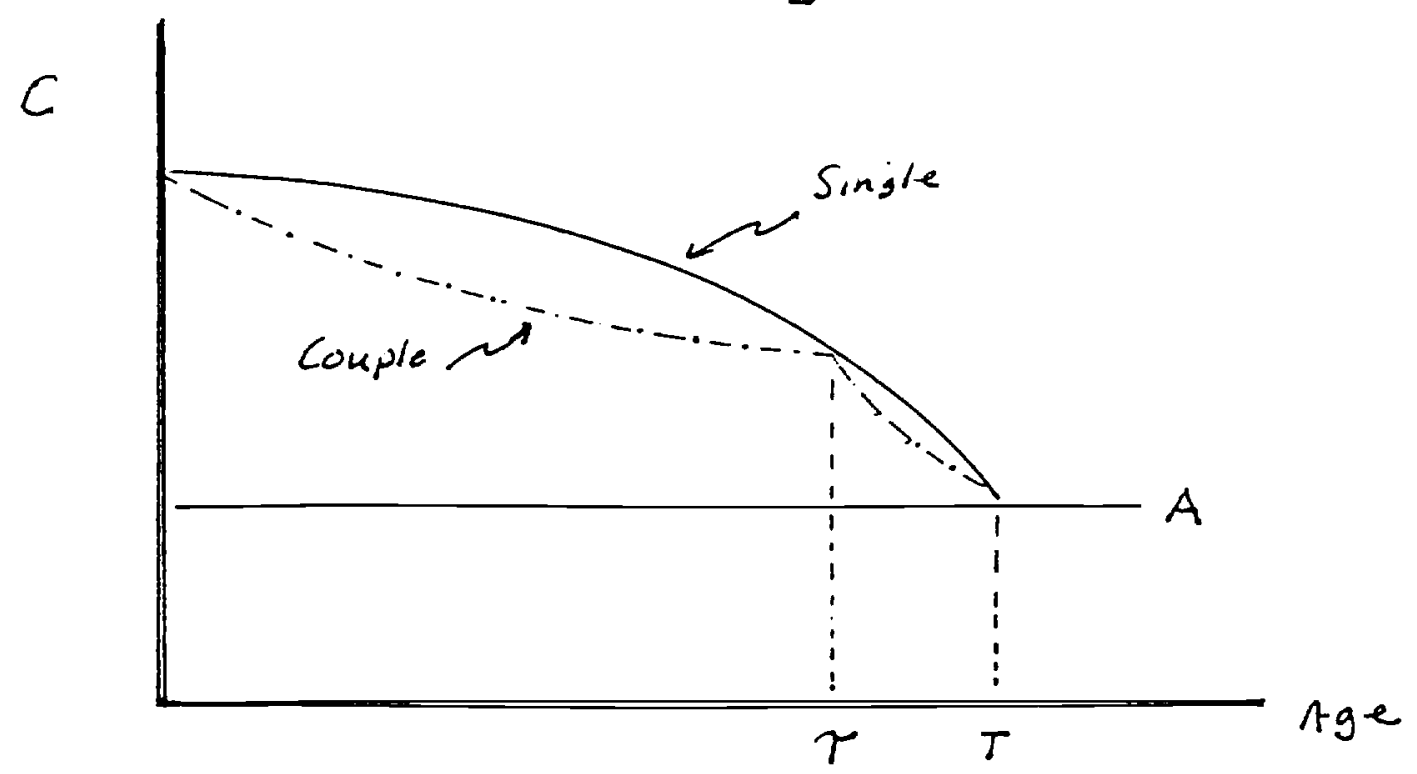

Fig. 12

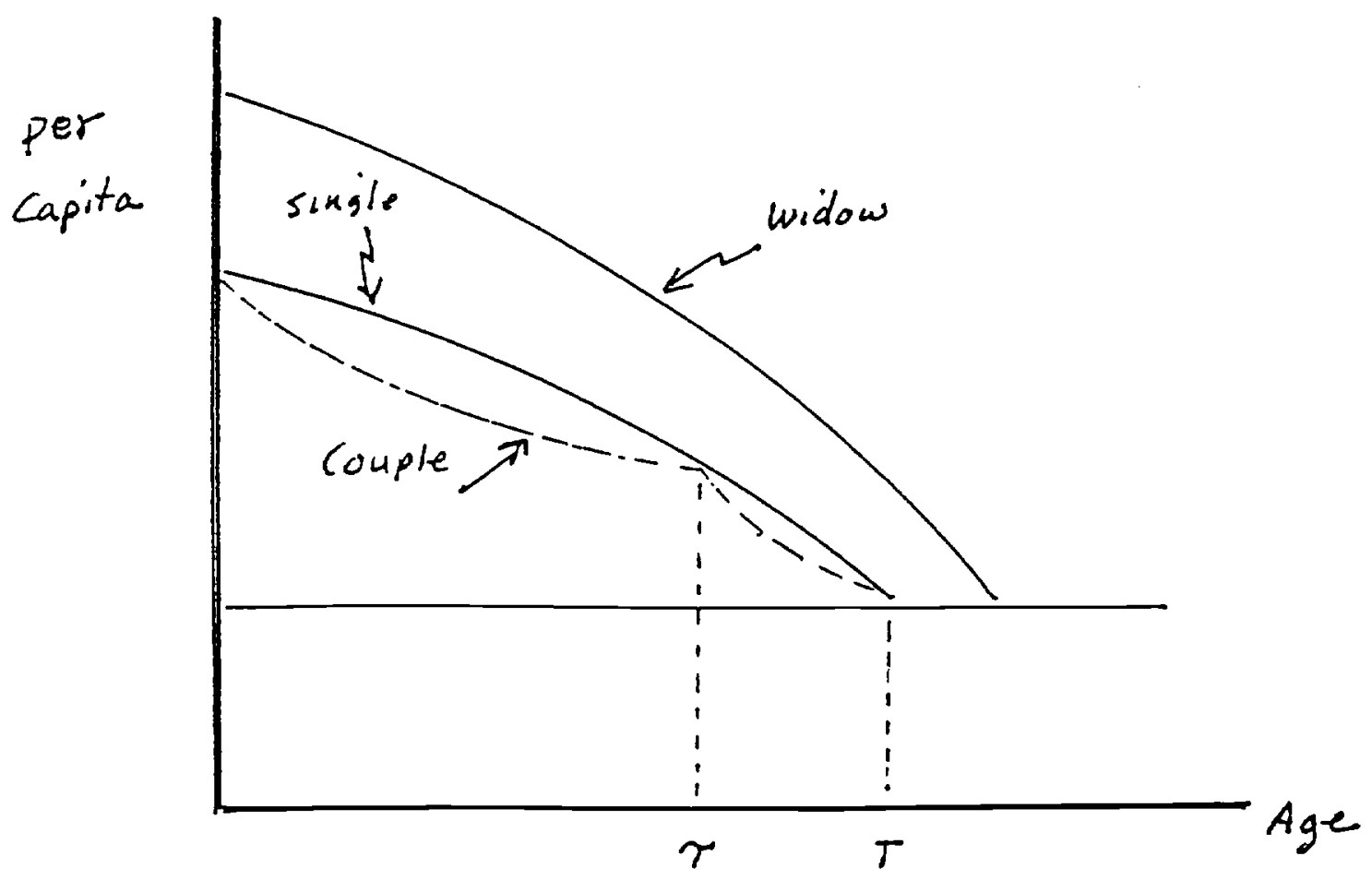


Fig 13

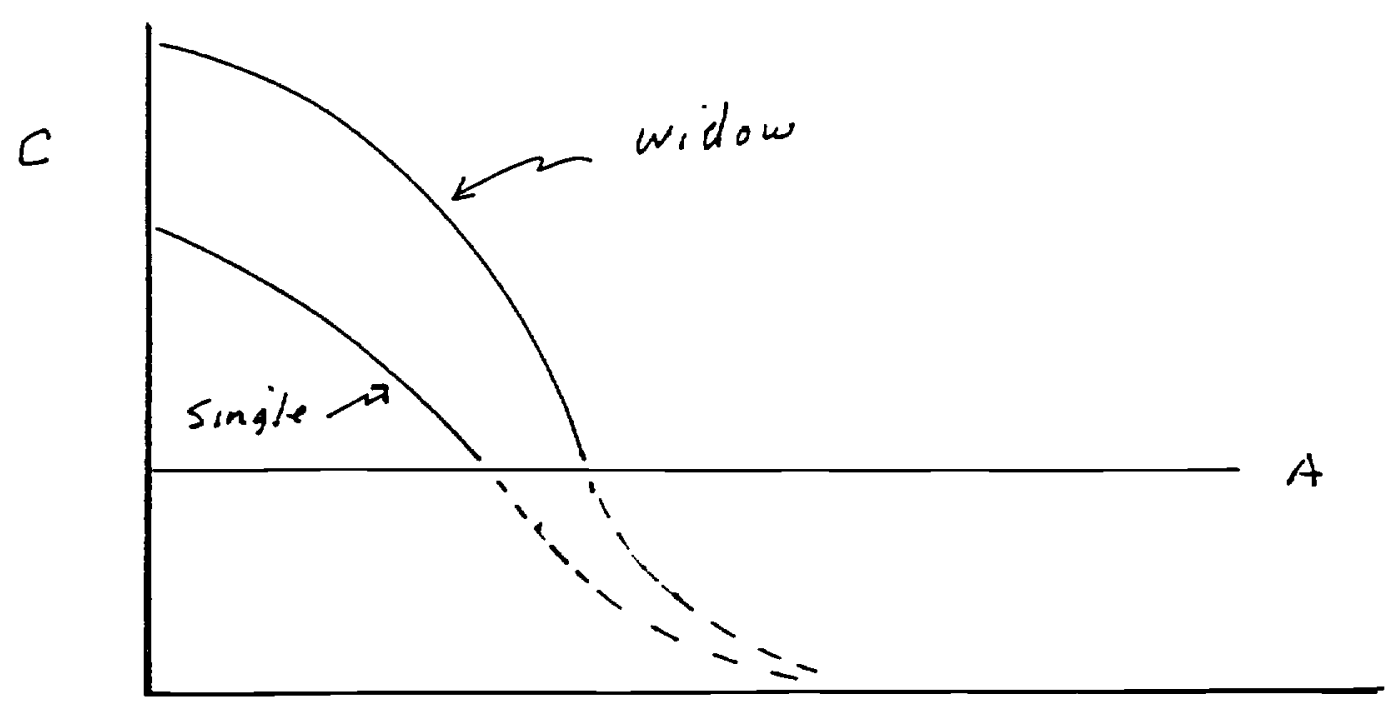

Fig 14

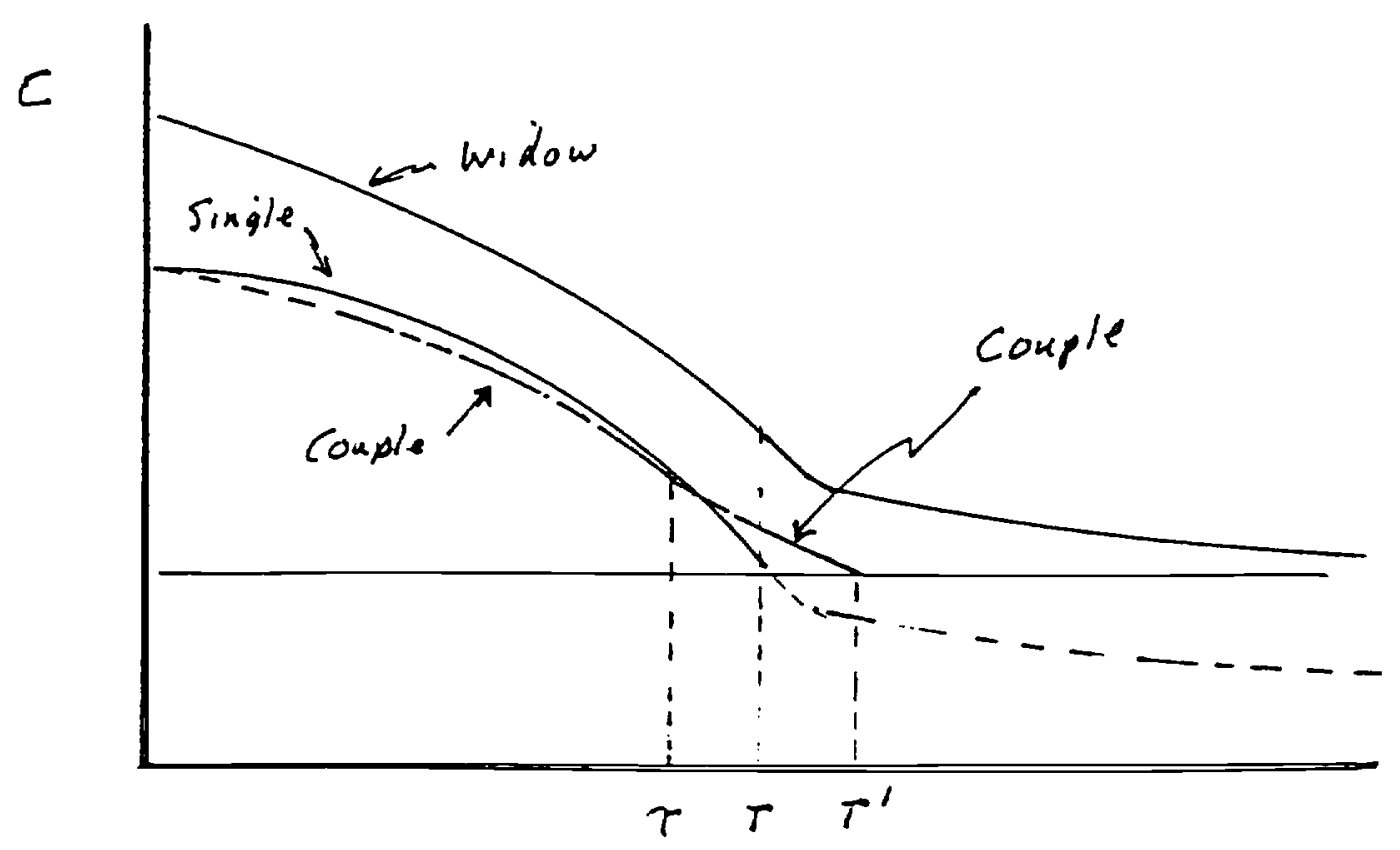

